\title{
MECHANICAL PROPERTIES OF FIRE-RETARDANT GLASS FIBER-REINFORCED POLYMER MATERIALS WITH ALUMINUM TRI-HYDRATE FILLER
}

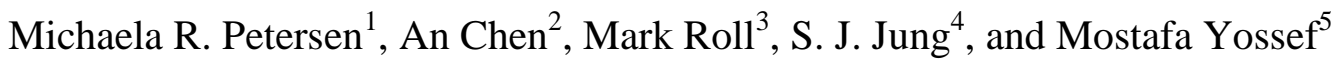

\begin{abstract}
Aluminum Tri-hydrate (ATH) can be effectively used to increase fire resistance of FiberReinforced Polymer (FRP) materials. This paper studies the effect of ATH filler on mechanical properties of Glass FRP (GFRP) material, based on compression, tension, shear and flexural test results from three types of GFRP materials with the amount of 0\% (control), 25\%, and 50\% ATH filler by weight of the resin. It was found that the control was the strongest for all tests except for flexure, which is $3 \%$ lower than the flexural strength of $25 \%$ ATH sample. The compressive strength dropped $19 \%$ and $25 \%$ for $25 \%$ and $50 \%$ ATH loadings, respectively, compared to the control. For shear and tensile strengths, the $25 \%$ ATH sample acted similarly to the control, but the 50\% ATH sample had a significantly lower strength. For stiffness, changing the additive amount from $0 \%$ to $50 \%$ had only small changes for compression, tension, and flexure. It can be concluded that adding ATH generally decreases the strength and makes FRP more brittle. The performance of a $25 \% \mathrm{ATH}$ loading is comparable to the control except compression, while a $50 \%$ ATH loading has a more significant effect on the mechanical properties of the GFRP. The data presented in this paper can be used to develop fire-resistant FRP systems.
\end{abstract}

\footnotetext{
${ }^{1}$ Formerly, Graduate Research Assistant, Department of Civil Engineering, University of Idaho, Moscow, ID 83844

${ }^{2}$ Assistant Professor, Department of Civil, Construction and Environmental Engineering, Iowa State University, Ames, IA 50011. E-mail: achen@ @iastate.edu (corresponding author)

${ }^{3}$ Assistant Professor, Department of Chemicals and Materials Engineering, University of Idaho, Moscow, ID 83844

${ }^{4}$ Professor, Department of Civil Engineering, University of Idaho, Moscow, ID 83844

${ }^{5} \mathrm{PhD}$ Candidate, Department of Civil, Construction and Environmental Engineering, Iowa State University, Ames, IA 50011.

(C) 2015. This manuscript version is made available under the Elsevier user license http://www.elsevier.com/open-access/userlicense/1.0/
} 
Keywords: A. Glass fibres; B. Polymer-matrix composites (PMCs); C. Mechanical properties; D. Mechanical testing; E. Aluminum Tri-Hydrate filler

\section{INTRODUCTION}

Fiber-Reinforced Polymer (FRP) consists of high-strength fibers (glass, carbon, aramid, boron, etc.) embedded in a polymer resin (polyester, vinyl ester, resin, etc.). It is high strength (from the fibers), durable (from the resin), and lightweight. In the last two decades, FRP has gained acceptance and popularity in civil infrastructure applications, including FRP bridge decks, internal FRP reinforcement for concrete and prestressed concrete structures, strengthening of reinforced concrete, masonry, timber and metal with externally bonded FRP, etc. [7].

Numerous studies have also been performed to determine the behavior of FRP for building applications, mostly focused on Carbon FRP (CFRP) and Glass FRP (GFRP). Among others, Mukhopadhyaya et al. [19] studied whether FRP could be used in conjunction with concrete and concluded that it could perform well as a flexural reinforcement for concrete beams. Mirmiran et al. [18] studied the effects that wrapping hybrid concrete beam-columns with FRP would have on the strength and ductility of the beams. Davalos et al. [12] investigated the durability and shear strength by testing the bond strength between the FRP and the wood under both wet and dry conditions. Chowdury et al. [11] looked into the remaining structural strength in building systems after a fire event. Herwig and Motavalli [15] studied the axial behavior of reinforced concrete beams that had been externally strengthened with either lightweight concrete or with unbounded GFRP wrapping, i.e., there was no adhesive or other connecting mechanism between the GFRP wrapping and the concrete. Pantelides et al. [21] investigated the performance of concrete panels reinforced with synthetic fibers, mild steel, and GFRP when subjected to blast 
loading. They also investigated the possibility of using a hybrid GFRP/steel concrete panel in order to develop composite action between a concrete-foam composite. The highlight of these efforts was the publications from the Committee of ACI 440, in particular, ACI 440.2R-08 [1], which provided a guide for the design and construction of externally bonded FRP systems for strengthening concrete structures.

However, unlike other civil infrastructure applications, buildings have stringent requirements on flame spread, smoke and toxicity, and fire ratings. Foster and Bisby [14] tested the bond strength between FRP and concrete and FRP to FRP via testing the ultimate tensile strength, elastic modulus, and failure strain at a range of temperatures. Their study showed that GFRP's bond strength begins to decrease dramatically after $300^{\circ} \mathrm{C}$ likely due to the glass transition temperature of the polymer being surpassed. Petersen [22] conducted a detailed study on the requirements from International Building Code [16] for FRP to be used for buildings. Based on their findings, FRP with regular resins cannot meet the requirements of flame spread, smoke and toxicity, and fire ratings. These issues are generically addressed in ACI 440.2R-08 [1] as: "FRPstrengthened structures should comply with all applicable building and fire codes. Smoke and flame spread ratings should be determined in accordance with ASTM E 84. Coatings can be used to limit smoke and flame spread." For fire, ACI 440.2R-08 [1] further states that "due to the low temperature resistance of most fiber-reinforced polymer materials, the strength of externally bonded FRP systems is assumed to be lost completely in a fire."

Although providing coating as suggested in ACI 440.2R-08 [1] can improve the fire performance, it is costly. A more cost-effective way to address this problem is to add fireretardant fillers to the resin, as discussed below. The resulting modified resins might even be cheaper than regular resins since some fillers are often less expensive than regular resins. 
One of the additives investigated was rice hull ash (RHA). Due to the high silica content in the RHA, it was theorized that RHA could be a good fire retardant when added to a polymer system. Chand et al. [9] investigated the implications of using RHA as an additive to polyester composites. The RHA was added to the resin using volume fractions and after curing, tensile and impact strength was measured. Because RHA is weak in tension, it was found to decrease the tensile strength of RHA-loaded samples. Also it was found that RHA decreases the impact strength of the system using the IZOD impact test. Unfortunately, when RHA is generated at low temperatures it has a black color, which absorbs heat and therefore is not conducive to utilization in green environments. Chakraverty et al. [8] aimed at completing the following objectives through their research: (1) to determine the effects of various acid treatments on process of removing metallic impurities from the RHA, and (2) to determine the effects of acid treatments and different furnace temperatures on the time required to obtain completely white RHA. While it was found that the acid wash did not affect the silica structure of the RHA, it also did not affect the time for complete combustion of the RHA in order to produce a white silica product.

Another additive that was investigated was nanoclay (NC). Nazare et al. [20] investigated the use of $\mathrm{NC}$ in polyester resin to reduce smoke generation and improve the fire resistance of the system. They found that the addition of NC helps reduce the flammability because the dispersion of clay in the polymeric matrices produces a nanocomposite structure which allows for reduced flammability as well as improved mechanical properties. In addition, the NC forms a char layer, which helps insulate the FRP below. It was noticed that for higher clay concentrations ( $>5 \%$ clay) in combination with flame retardants, the crosslinking reaction, or the development of the nanocomposite structure in the nanoclays, was noticeably slower or halted completely. In addition to this problem, the resin also became more plastic and had an increased cure time when 
the clay concentrations were high. From X-ray diffraction, it was found that little to no nanocomposite was formed. From the cone calorimetry test, it was found that the time to ignition was improved by 102 seconds. Therefore, nanoclay is a viable option for fire resistance in the GFRP.

Wu et al. [23] looked into using NC in conjunction with epoxy adhesives to provide fire resistant properties for the epoxy. This study investigated various flame spread and hightemperature exposure tests. They found that $\mathrm{NC}$ can greatly improve the flame retardancy of epoxy systems at filling levels of 2\%-3\%. They also found that NC which was distributed into the epoxy using a mixer was better at improving fire properties than NC distributed by hand.

Intumescents were studied by Kandola et al. [17] to see how they changed the burning mechanism of composites with polyester resin. Intumescents are often found in paints and ceramics, and therefore may be incorporated into a building system. They found that intumescents significantly decreased the flaming behavior of the resins tested. However, the decrease was not as significant as expected. Also, they found that the intumescents did not help the structural integrity of the composite. Therefore, they suggested that intumescents be used as a protective coating on thick laminates.

Dholakiay [13] investigated the effects of the following four different additives: (1) hydroxyapatite or calcium phosphate, (2) zinc borate, (3) class C fly ash, and (4) antimony trioxide. They were tested for their fire resistance using LOI, TGA and IR spectroscopy. The materials are considered self-extinguishing if the LOI is greater than 26 , and all of the composites tested had an LOI in the range of 25-26. It was also found that as the amount of fillers increases, so did the fire resistance of the composite. They concluded that while fly ash was a good additive, hydroxyapatite and zinc borate were better for increasing LOI. From the 
TGA, it was found that composites containing filler have a better thermal stability. Mechanical properties were tested for the samples using Rockwell hardness test and flexural strength tests. From these tests, it was found that the mechanical properties increased as the filler content increased. The exception to this was for antimony trioxide and fly ash.

Liang et al. [27] studied mechanical properties and flame retardancy of polypropylene (PP) composites filled with Microencapsulated Red Phosphorus (MRP) and Magnesium Hydrate $\left[\mathrm{Mg}(\mathrm{OH})_{2}\right] /$ Aluminum Hydrate $\left[\mathrm{Al}(\mathrm{OH})_{3}\right]$. They found that the increase of the weight fraction of MRP increases the index of limit oxygen, the rank of smoke density, the Young's modulus and tensile elongation; but decreases the horizontal burning speed and tensile yield and fracture strengths.

Correia et al. [25] conducted an experimental program to study the behavior of GFRP profiles subjected to fire. Calcium silicate board, vermiculite/perlite based mortar and intumescent coating were used to provide fire protections, which was found to be effective in reducing the temperature throughout the profiles. The protected GFRP pultruded profiles achieved a fire resistance of 60-76 minutes, comparing to 38 minutes for unprotected ones. The addition of water cooling system could further increase the fire resistance to 120 minutes.

Chen et al. [29] developed a new glass fiber/bismaleimide (GF/BMI) composite that could improve the flame retardancy while achieving higher mechanical properties and lower dielectric loss. A new flame retardant resin (BDDP) was added to glass fibers. It was found that the interlaminar shear strength of the GF/BDDP composites were 1.4-1.9 times of those of GF/BMI composites and the flame retardency was improved from UL 94 V-2 to V-0 grade.

Zhang et al. [28] investigated the mechanical properties and flame retardancy of wood-fiber/ polypropylene (PP) composites. Cone colorimeter data (CONE) and LOI results showed that 


\begin{abstract}
Ammonium Polyphosphate (APP) and silica are effective flame retardant materials for woodfiber/PP composites.
\end{abstract}

Jeencham et al. [26] studied the efficiency of the following flame retardant fillers: APP, $\mathrm{Mg}(\mathrm{OH})_{2}$, zinc borate $(\mathrm{Zb})$, and a combination of $\mathrm{APP}, \mathrm{Mg}(\mathrm{OH})_{2}$ and $\mathrm{Zb}$ in sisal fiber/PP composite. It was found that the addition of APP or a combination of APP and Zb could improve the flame retardancy of sisal fiber/PP composites.

Rowen et al. [24] conducted Cone Calorimeter and ASTM E 84 flame and smoke tests to compare performances among GFRPs with standard resin, which acted as a reference, and resins with three different additives. Sample 1 contained pultruded brominated resin panel with polyester veil, sample 2 contained pultruded panel with alumina trihydrate (ATH) and intumescent veil, and sample 3 consisted of pultruded panel with ATH and expandable graphite intumescent veil. It was concluded that the third sample achieved the best performance based on cone tests, where Peak Heat Release Rate (PHRR) and Average Hea Release Rate (AHRR) were at $47 \mathrm{~kW} / \mathrm{m}^{2}$ and $21 \mathrm{~kW} / \mathrm{m}^{2}$, which were significantly lower than the values of $185 \mathrm{~kW} / \mathrm{m}^{2}$ and $85 \mathrm{~kW} / \mathrm{m}^{2}$ for sample 1. Improved performance was also observed based on ASTM E 84 test results, where sample 3 achieved Flame Spread Index (FSI) of 20 and Smoke-development Index (SDI) of 125 compared with FSI of 25 and SDI of 985 for sample 1.

Similar conclusions were drawn by Petersen [22]. They compared performances of a wide range of fillers, which included: ATH, a mixture of boric acid and rice hull ash (BA/RHA), coarse graded gypsum (CG), coarse graded limestone (CLS), a mixture comprised of 60\% BA, 20\% RHA, 10\% limestone, and 10\% ATH (Conc), fine graded gypsum (FG), fine graded limestone (FLS), nanoclays (NC), and rice hull ash (RHA). In addition, two controls were created with no additives to the resin, one with 1\% MEKP hardener and the other with 5\% 
MEKP hardener. They concluded that by adding ATH to the resin in different amounts, the heat resistive properties of the FRP could be increased. The time to ignition for the $50 \%$ ATH was 6 seconds, which was a 4 second improvement from the control samples. Additionally, it was found that with the additional of $\mathrm{ATH}$, the char layer was generated, the quantity of the smoke produced was low, and flame spread could be significantly decreased during fire tests.

As shown above, extensive studies has been conducted on the fire performance of FRP with fillers and shown that the fire resistance of the FRP can be increased by adding various additives to the resin. However, there is only limited study on the effect of the fillers on mechanical behavior, including stiffness and strength, of the FRP system. Other than the preliminary study from Dholakiay [13] as described above, Aziz et al. [6] investigated how modifying polyester resins with additives could change the mechanical properties, glass transition temperature, fracture surface, and bond performance of the systems. They found that adding kenaf, a plant fiber, could improve the mechanical behavior of the composites. However, to the authors' knowledge, no study is available on the effect of ATH filler on the mechanical properties of the GFRP, which is the objective of this study. To achieve this, comprehensive tests were conducted, as described next.

\section{EXPERIMENTAL PROGRAM}

\subsection{Testing Plan}

The experimental program consisted of compression, tension, shear and flexural tests, conducted on FRP coupon samples made of resins with three different amount of ATH, namely $0 \%$ (control), 25\%, and 50\% ATH by weight, with five samples for each test. 


\subsection{Materials}

404 isophthalic resin, A202 ATH, and E-glass Chopped Strand Mat (CSM) were used to manufacture the samples. The material properties are shown in Table $\mathbf{1}$.

\subsection{Workability Test}

In past research [13], it was found that as the concentration of additives increased in the resin, so did the fire resistance of the GFRP until the workability was compromised. Therefore, the workability limits need to be found for ATH in order to determine the optimal loading amount. A workability test was performed and the results are shown in Table $\mathbf{2}$, where samples mixed with ATH were rated on a scale of one to ten with ten being very runny, and one being completely unworkable. It was determined that four was the ideal workability for $51 \mathrm{~g} / \mathrm{m}^{2}(1.5$ $\mathrm{oz} / \mathrm{yd}^{2}$ ) of chopped strand mat given that at this workability the resin was still able to completely penetrate the fibers. These tests were conducted in parts per hundred (PPH). For example, 100 PPH means that the resin is 50\% resin and 50\% ATH. From Table 2, it can be seen that at 25\% $\mathrm{ATH}$, or $50 \mathrm{PPH}$, the resin had a workability of 8 and at $50 \% \mathrm{ATH}$, or $100 \mathrm{PPH}$, the resin had a workability of 4 . Therefore, these two were selected for further testing along with a control which contained $0 \%$ ATH. Further information on the workability tests can be found from Petersen [22].

\subsection{Sample Fabrication}

Samples were cast using vacuum bagging methods. First, a layer of visqueen was placed down, followed by a breather cloth and peel ply. Next, one layer of $102 \mathrm{~g} / \mathrm{m}^{2}\left(3 \mathrm{oz} / \mathrm{yd}^{2}\right)$ chopped strand fiber was laid down, and the appropriate amount of resin, by weight, was added. After the 
resin had been applied, the system was pressed down to eliminate air from the system. The process with the resin and the fiber was repeated until the appropriate number of layers had been reached. After the FRP was cast, peel ply was placed on the top, and then another layer of breather cloth. Finally, the visqueen was folded on the top, and the bag was sealed. Before the vacuum bag was opened and the FRP was removed, the FRP was allowed to cure for a minimum of twenty-four hours. Examples of this process can be seen in Figures $\mathbf{1 A}$ and $\mathbf{1 B .}$

In order to make the FRP samples, three $61 \times 61 \mathrm{~cm}^{2}\left(2 \times 2 \mathrm{ft}^{2}\right)$ samples were cast with quantities of $0 \%, 25 \%$, and $50 \%$ ATH by weight of the total amount of resin, i.e., if $50 \%$ was used, $50 \%$ of the system was resin and the other $50 \%$ was ATH. Using a volumetric fraction of the fiber $\left(\mathrm{V}_{\mathrm{f}}\right)$ of 0.1877 following a previous study [10], for each $102 \mathrm{~g} / \mathrm{m}^{2}$ (3 oz/yd ${ }^{2}$ ) layer of fiberglass, the required weight of the resin was determined to be $894 \mathrm{~g} / \mathrm{m}^{2}\left(26.37 \mathrm{oz} / \mathrm{yd}^{2}\right)$ per layer. Since the desired thickness of each panel was $6.4 \mathrm{~mm}(0.25$ inches $)$, the required number of plies was calculated to be four.

The resin additive mixture was created by first weighing out the amount of ATH to be used. Next, resin was measured and the premeasured ATH was added. The ATH was then carefully mixed into the resin in order to avoid creating air bubbles. Next, 5\% MEKP hardener was added by weight of the total amount of resin. This was then also carefully mixed, and the resin and additive was poured onto the FRP and smoothed evenly over the entire surface. After the resin had been spread over the FRP, a roller was used to eliminate air pockets between layers of fiberglass. This process was repeated for each layer of FRP. The goal was to achieve a $6.4 \mathrm{~mm}$ (0.25 inches) thickness. However, the 50\% ATH system was thicker, as will be shown next, because the resin was too thick to properly soak the fibers. 


\subsection{Sample details}

After the composite had cured for a minimum of twenty-four hours, it was removed from the vacuum bag and placed under a fume hood until it was cut into the testing samples. From each $61 \times 61 \mathrm{~cm}^{2}\left(2 \times 2 \mathrm{ft}^{2}\right)$ panel, five samples for each test were cut according to their ASTM standard measurements. Compression samples were cut to be 12.7 x $81.3 \mathrm{~mm}^{2}\left(0.5 \times 3.2 \mathrm{in}^{2}\right)$, as can be seen in Figure 2. Tension samples were 25.4 x $254 \mathrm{~mm}^{2}\left(1 \times 10 \mathrm{in}^{2}\right)$ tabs with $76.2 \mathrm{~mm}$ (3 inches) tabs at each end. After the $76.2 \mathrm{~mm}$ (3 inches) tabs, the samples were narrowed down to $12.7 \mathrm{~mm}$ (0.5 inches) wide, as shown in Figure 3. The samples for shear were $19.1 \mathrm{x} 76.2 \mathrm{~mm}^{2}$ $\left(0.75 \times 3.0 \mathrm{in}^{2}\right)$ tabs, with $45^{\circ}$ notches cut from the middle of the span, as shown in Figure 4. Flexural samples were cut to be $50.8 \times 381 \mathrm{~mm}^{2}\left(2 \times 15 \mathrm{in}^{2}\right)$, as shown in Figure 5.

\subsection{Test Setup}

All tests were conducted on an MTS 318.10 machine with a Flex Test SE control unit. Five samples were tested for each type of the test. Loading rates were specified by respective ASTM standards, as shown in Table 3. Loads and displacements were recorded by the MTS machine and a separate National Instruments Data Acquisition System (DAS) was used to record the strain.

\subsection{Test Methods}

\subsubsection{Compression (ASTM D 695) [3]}

For compression test, the samples were placed in the fixture as shown in Figure 6. The bolts were then hand tightened to the point that there was a limited amount of resistance. This was done because if the bolts were loose then the samples could buckle, but if they were too tight 
then the fixture and the sample could form a steel-GFRP composite. The buckling case would provide data resulting in strength that was less than the actual strength of the composite, while the composite case would create a strengthened system, and therefore the values for the strength would be greater than the actual strength of the FRP.

\subsubsection{Tension (ASTM D 638) [5]}

For tension test, Syntech grips were used. The grips were able to clamp samples that were up to $6.4 \mathrm{~mm}(0.25$ inches $)$ thick. Therefore, the samples were filed to a thickness of $5.8 \mathrm{~mm}(0.23$ inches) in order to allow the samples to fit into the grips and prevent failures from occurring at the grips. For testing, the grips were hand tightened around the samples until a force of $222 \mathrm{~N}$ (50 lbs) was applied, and then the test was run. The system for the tension testing can be seen in Figure 7.

\subsubsection{Shear (ASTM C 1292) [4]}

Each shear sample was inserted into the fixture as can be seen in Figure 8. Care was taken to align the sides of $\mathrm{V}$-notches at the appropriate location on the shear fixture, so that the start of the bottom V-notch would line up with where the fixture started to slope. In addition, the front of the samples was flush with the front of the fixture.

\subsubsection{Flexure (ASTM D 790) [2]}

For flexure, a three point bending test was performed using a custom-made fixture with a span of $279 \mathrm{~mm}$ (11 inches), as shown in Figure 9. Therefore, the sample extended past the fixture $51 \mathrm{~mm}$ ( 2 inches) on each end. The load was applied at the center of the sample. 


\subsection{Strain Gage Placement}

Strain gages were placed on the compression, tension and flexural samples. No strain gages were used for shear samples. However, accuracy was checked by comparing the results to previous studies. For each test, strain gages were attached to four of the five samples for each additive quantities $(0 \%, 25 \%$, and $50 \%)$. For compression, one strain gage was placed at the center of the sample, as shown in Figure 6. For tension, a strain gage was placed at the middle of each sample, as shown in Figure 10. For flexure, two strain gages were attached to the top and bottom at the center of each sample, as can be seen in Figure $\mathbf{1 1 .}$

\section{TEST RESULTS}

\subsection{Compression (ASTM D 695) [3]}

\subsubsection{Stiffness and Strength}

For compression test, force-displacement curves as shown in Figure $\mathbf{1 3}$ were obtained from MTS machine, and stress-strain curves were developed from both the DAS and forcedisplacement curves from the MTS machine, as shown in Figure 12, where good correlations can be observed between the two systems. However, the strain gages stopped working before the samples failed. Therefore, the data from the MTS machine were used to calculate the strain to develop complete stress-strain curves.

It is noted that the force-displacement curves in Figure $\mathbf{1 3}$ show that the strength of 50\% ATH sample is higher. This is because the 50\% ATH samples were $2.4 \mathrm{~mm}(0.094$ inches $)$ and $2.6 \mathrm{~mm}$ (0.103 inches) thicker than the control and 25\% ATH samples, respectively, as shown in Table 4. Therefore, the stress-strain curves from the MTS machine shown in Figure 14, which 
take into account the section area differences, are better representative of the actual strength of the composites. Also, from this graph, the modulus of elasticity for each additive amount was calculated using a linear trend line. In order to add the trend line, first the initial section due to equipment settlement was removed, and then a best fit line was created, as shown in Figure $\mathbf{1 5}$ for a representative sample. The equation for the best fit line can be seen on the graph, where the slope is the modulus of elasticity. The modulus of elasticity for each group is reported in Table $\mathbf{4}$, and a comparison between the control, 25\%, and 50\% ATH including their error bars is shown in Figure 16, which indicates that the compressive modulus of elasticity is fairly similar from the control to the $50 \% \mathrm{ATH}$, with a maximum of $5 \%$ difference.

Table 4 summarizes the values for the maximum forces, stresses, and displacements for all the three additive amounts as well as those from previous research [10]. The maximum stress is higher than those from previous tests [10] since the resin and fiber are different, but they are still within a similar range. Similar to Figure 13, the area has not been taken account in the forces, and therefore indicates that 50\% ATH has the highest ultimate load. But when adjusted for the differences in the cross section areas of the samples, it can be seen from Table $\mathbf{4}$ and Figure $\mathbf{1 7}$ that the composite with the highest maximum stress is the control with an ultimate stress of 178 MPa (25.8 ksi). The next strongest is the $25 \%$ ATH which has an ultimate stress of $145 \mathrm{MPa}$ (21.0 ksi), followed by the 50\% ATH which has an ultimate stress of $138 \mathrm{MPa}(20.0 \mathrm{ksi})$. Therefore, there is a $19 \%$ reduction in ultimate stress from the control to the $25 \% \mathrm{ATH}$, and a $23 \%$ reduction from the control to the $50 \% \mathrm{ATH}$.

Although the maximum deflections are reported in Table 4, they cannot be directly compared and used to calculate the maximum strain since they include the initial settlement. However, because the load-displacement curves are linear excluding the initial part due to the equipment 
settlement, i.e., the materials are elastic in compression, the maximum strain can be calculated as the maximum stress divided by the modulus of elasticity, with values shown in Table 4 . It can be seem from Figure 18 that, comparing to control samples, the maximum strain drops $14 \%$ and $20 \%$ for the $25 \%$ ATH and $50 \%$ ATH samples, respectively, indicating that adding ATH generally makes the samples more brittle in compression.

\subsubsection{Failure Mode \\ There were three crack patterns that occurred in all the three ATH amounts, as can be seen in Figure 19, in which the cracks have been highlighted with a pink dye for visibility. The crack patterns did not seem to have significant impact on the maximum stress or displacement of their respective composite groups.}

\subsection{Tension (ASTM D 638) [5]}

\subsubsection{Stiffness and Strength}

Similar to compression test, force-displacement curves were created from the data obtained from the MTS machine, and stress-strain curves were developed from both the MTS machine and the DAS. As shown in Figure 20, good correlations can be observed between the two systems, but the strain gages stopped working before the samples failed. Therefore, the displacement data from the MTS machine were used to calculate strain in the following analysis.

Unlike the results from the compression test, there was no thickness change between the control, the 25\% ATH, and 50\% ATH samples since they were all cut to have a constant thickness in order to fit in the tension grips, as shown in Table 5. Therefore, the forcedisplacement curves, as shown in Figure 21, and the stress-strain curves, as shown in Figure 22, 
are similar, both correctly representing that the $50 \%$ ATH sample is significantly weaker than the other two composites. Also, from Figure 21 and Figure 22, it can be seen that the control and the 25\% ATH sample act in similar fashions, with similar slopes and the maximum loads and stresses.

Using the same methods as described for compression tests, modulus of elasticity can be calculated, as shown in Table $\mathbf{5}$ and Figure 23. It can be seen that all samples are fairly similar, with the 25\% ATH sample 6\% higher and the 50\% ATH sample 5\% lower than the control samples.

Table 5 compares the differences in strength among all three laminates and those from previous tests. Figure $\mathbf{2 4}$ presents the difference in maximum stress with error bars for the various additive amounts. It can be seen that the control is able to hold the most load and stress. The maximum stresses of the $25 \%$ and $50 \%$ ATH samples are $9 \%$ and $47 \%$ lower than the control samples, respectively.

The maximum strain can be calculated in the same say as compression test, with values shown in Table 5. It can be seem from Figure 25 that, comparing to control samples, the maximum strain drops $14 \%$ and $44 \%$ for the $25 \%$ ATH and $50 \%$ ATH samples, respectively, indicating that adding ATH also makes the samples more brittle in tension.

\subsubsection{Failure Mode}

For tension, the fracture type was consistent throughout all the resin types. A crack began in the center of the sample, and then propagated across the $12.7 \mathrm{~mm}$ ( 0.5 inches) mid-section until pull-apart occurred, as shown in Figure 26. 


\subsection{Shear (ASTM C 1292) [4]}

\subsubsection{Stiffness and Strength}

Similar to compression tests, force-displacement curves were obtained from the data from the MTS machine for the shear tests, as shown in Figure 27. Due to time constraints and back order of the shear strain gages, strain gages were not used for shear samples; therefore no stress-strain curve was developed. However, in order to verify the data, the maximum stresses were calculated and compared to previous research as can be seen in Table $\mathbf{6}$, which also reports the maximum forces and displacements recorded during the test. Figure $\mathbf{2 8}$ shows the difference in the maximum stress among different additive amounts. As can be seen from Table $\mathbf{6}$ and Figure 28, the strengths of the control and 25\% ATH samples were about the same, but there was a reduction in strength of $27 \%$ from the control to $50 \%$ ATH samples.

\subsubsection{Failure Mode}

The three different loading amounts all had slightly different failure types as can be seen in Figure 29. The control failed with no sign of delamination, while both $25 \%$ and $50 \%$ ATH samples had shear failures and also slight delamination failures. In addition, the 50\% ATH sample had one sample that had a catastrophic failure. The failure started at the bottom of the samples at the V-notch, and then propagated up to the top of the sample.

\subsection{Flexure (ASTM D 790) [2]}

\subsubsection{Stiffness and Strength}

Similar to compression test, load-displacement curves were obtained from the data from the MTS machine. However, due to the nature of the flexural test, stress-strain curves were only 
created from the strain data from the DAS combined with the stress data from the MTS and no stress-strain curve was developed solely from the MTS data. The stress-strain curves from the DAS can be seen in Figure 31, and the force-displacement curve from the MTS can be seen in Figure 30. Unlike elastic behavior observed from previous tests, it is noted that the 50\% ATH samples assume a nonlinear behavior. This is probably because the samples are thicker, as shown in Table 7, and much stiffer. Any small amount of slippage at the support will affect the displacement.

Similar to the compression test, the strain gages stopped working before failure occurred. Therefore, the force-displacement curves were used to calculate the stiffness. The mid-span deflection of the sample under 3-point loading can be calculated as:

$$
\Delta=\frac{P L^{3}}{48 E I}
$$

where $\Delta$ is the displacement from the MTS machine, $P$ is the force from the MTS machine, $L$ is the distance between supports on the sample, $E$ is the modulus of elasticity, and $I$ is the moment of inertia as:

$$
I=\frac{b h^{3}}{12}
$$

where $b$ is the width and $h$ is the depth of the sample, as shown in Figure 5.

From the initial linear region in each load-displacement curve, slope of the curve, $P / \Delta$, can be obtained. From Eq. (1), the flexural modulus of elasticity can be calculated using:

$$
E=\frac{P}{\Delta} \times \frac{L^{3}}{48 I}
$$


The results from these calculations are listed Table 7. A comparison of modulus of elasticity from the control to the other additive amounts can be seen in Figure 32, which shows that the control and 25\% ATH samples are similar, but the modulus of 50\% ATH is $11 \%$ lower than the control sample.

Table 7 summarizes the maximum forces, stresses, deflections and the modulus of elasticity. The maximum stresses with their error are shown in Figure 33. It can be seen that strength of the control and 25\% ATH are about the same, with 3\% difference. Comparing to control samples, there is a decrease of $21 \%$ for $50 \%$ ATH samples.

\subsubsection{Failure Modes}

The fracture types for all three quantities of ATH were fairly similar. The crack first formed at the middle of the span, and then propagated both upwards and across the sample, as shown in Figure $\mathbf{3 4}$ and Figure 35, where Figure $\mathbf{3 4}$ shows the bottom of the samples and Figure $\mathbf{3 5}$ shows the side of the samples. The failure initiated from the bottom of the sample and then spread up to the top. The fractures are dyed pink for better visibility.

\section{DISCUSSION}

As shown above, adding ATM generally decreases the strength of GFRP. Although the strength is decreased, it is still high enough (about $1 / 3$ of the strength of the steel) to be used for structural applications. The difference is that more materials are required to take the same load. Additionally, the strength reported in this paper was based on the specific fiber volume fraction, $V_{f}$, adopted in this study. Higher strength can always be achieved with higher $V_{f}$. 


\section{CONCLUSIONS}

Three layups containing varying amounts of ATH ranging from $0 \%, 25 \%$ to $50 \%$ by weight were tested in order to evaluate the effects of ATH on the mechanical properties of FRP. The tests, including compression, tension, shear and flexure, were performed according to ASTM standards. The following conclusions can be drawn from this study:

1) Strengthwise, the control was the strongest for all of the tests except for flexure, which is $3 \%$ lower than the flexural strength of $25 \%$ ATH sample. For compression, there is a $19 \%$ and $25 \%$ reduction from the control to $25 \%$ and $50 \%$ ATH samples, respectively. For tension, shear, and flexure, the $25 \%$ ATH sample acted similarly to the control. However, the 50\% ATH sample had a significantly lower maximum stress.

2) The moduli of elasticity were compared for all three additive loadings, and it was found that changing the additive amount of ATH has insignificant effect on stiffness.

3) Adding ATH generally decreases the strength and makes the FRP more brittle.

4) Using 25\% ATH by weight in conjunction with isophthalic does not have a significant effect of the stiffness and strength comparing to control samples except compression, while 50\% ATH has more significant effect.

The data presented in this paper can be used to develop fire-resistant FRP systems. It should be pointed out the findings are based on the ATH and resin used in the study. Further study is recommended for other types of fire-retardant fillers. Other properties, such as impact properties, are also important for FRP material, which deserves further study. 


\section{ACKNOWLEDGEMENTS}

We gratefully acknowledge the US Department of Energy for financial support. We appreciate the help from Dean Larry Stauffer (College of Engineering) and Chair Richard Nielsen (Department of Civil Engineering) from University of Idaho. We thank Dr. Lloyd Smith

(Washing State University), Dr. Pizhong Qiao (Washington State University) and Dr. Edwin Odom (University of Idaho) for their testing fixtures and advice. We also thank Tony Parris, Nicolas Pena and Dallas Roberts for helping with the test.

\section{REFERENCES}

[1] ACI 440.2R-08. Guide for the Design and Construction of Externally Bonded FRP Systems for Strengthening Concrete Structures, American Concrete Institute, Farmington Hills, MI.

[2] American Society for Testing and Materials. (2013). Stamdard Test Methods for Flexural Properties of Unreinforced and Reinforced Plastics and Electrical Insulating Materials. In ASTM D 790 .

[3] American Society for Testing and Materials. (2013). Standard Test Method for Compressive Properties of Rigid Plastics. In ASTM D 695.

[4] American Society for Testing and Materials. (2013). Standard Test Method for Shear Strength of Continuous Fiber-Reinforced Advanced Ceramics at Ambient Temperatures. In ASTM C 1292.

[5] American Society for Testing and Materials. (2013). Standard Test Method for Tensile Properties of Plastics. In ASTM D 638.

[6] Aziz, S. H., Ansell, M. P., Clarke, S. J., \& Panteny, S. R. (2005). Modified Polyester Resins for Natural Fibre Composites. Composites Science and Technology, 65, 525-535.

[7] Bakis, C. E. , Bank, L. C., Brown, V. L., Cosenza, E., Davalos, J. F., Lesko, J. J., Machida, A., Rizkalla, S. H., and Triantafillou, T. C. (2002). Fiber-Reinforced Polymer Composites for 
Construction-State-of-the-Art Review. Journal of Composites for Construction, ASCE, 6(2), 7387.

[8] Chakraverty, A., Mishra, P., \& Banerjee, H. (1988). Investigation of combustion of raw and acidleached rice hush for production of pure amorphous white silica. Journal of materials Science, $21-24$.

[9] Chand, N., Dan, T., Verma, S., \& Rohatgi, P. (1987). Rice husk ash filled-polyester resin composites. Journal of materials Science Letters, 733-735.

[10] Chen, A., \& Davalos, J. F. (2010). Strength Evaluations of Sinusoidal Core for FRP sandwich Bridge Deck Panels. Composite Structures, 1561-1573.

[11] Chowdhury, E. U., Bisby, L. A., Green, M. F., \& Kodur, V. K. (2008). Residual Behavior of Fire-Exposed Reinforced Concrete Beams Prestrengthened in Flexure with Fiber-Reinforced Polymer Sheets. Composites for Construction, 61-68.

[12] Davalos, J. F., Qiao, P., \& Trimble, B. S. (2000). Fiber-Reinforced Composite and Wood Bonded Interfaces: Part1. Durability and Shear Strength. American Society for Testing and Materials, 224-231.

[13] Dholakiya, B. Z. (2009). Use of non-traditional fillers to reduce flammability of polyester resin composites. Kategorizirani Radovi, 10-17.

[14] Foster, S. K., and Bisby, L. A. (2008). Fire Survivability of Externally Bonded FRP Strengthening Systems. Composite Construction, 553-561.

[15] Herwig, A., \& Motavalli, M. (2012). Axial Behavior of Square Reinforced Concrete Columns Strengthened with Lightweight Concrete Elements and Unbonded GFRP Wrapping. Composites for Construction, 747-752.

[16] Internaion Building Code (2012), International Code Coucil, Washington D.C. 
[17] Kandola, B. K., Horrocks, A. R., Myler, P., \& Blair, D. (2002). The Effects of Intumescents on the Burning Behavior of Polyester-Resin-Containing Composites. Composites: Part A, 33, 805-817.

[18] Mirmiran, A., Shahawy, M., \& Samaan, M. (1999). Strength and Ductility of Hybrid FRPConcrete Beam-Columns. Structural Engineering, 1085-1093.

[19] Mukhopadhyaya, P., Swamy, N., \& Lynsdale, C. (1998). Optimizing Structural Response of Beams Strengthened with GFRP Plates. Composites for Construction, 87-95.

[20] Nazare, S., Kandola, B., \& Horrocks, A. (2006). Flame-retardant unsaturated polyester resin incorporating nanoclays. Polymers for Advanced Technologies, 294-303.

[21] Pantelides, C. P., Garfield, T. T., Richins, W. D., Larson, T. K., \& Blakeley, J. E. (2012). Behavior of Concrete Panels Reinforced with Synthetic Fibers, Mild Steel, and GFRP Composites Subjected to Blasts. Idaho Falls: Idaho National Laboratory.

[22] Petersen, M. R. (2014). Evaluations of Fire-Retardent Fiber-Reinforced Polymer Materials for Building Application, MS Thesis, University of Idaho, Moscow, ID.

[23] Wu, L., Hoa, S. V., \& Wang, H. (2007). Improvement of Flammability Resistance of Epoxy Adhesives used in Infrastructure Applications. Canadian Journal of Civil Engineering, 34, 323330.

[24] Rowen, J., Herring, B., and Dembsey, N. (2010). "Systems 648 Approach to Creating FRP to Meet 2009 International Building Code Requirements for Interior Composites.” Composite Technology Magazine, 〈http://www.avtecindustries.com/IBC_Requirements_for_Interior_Composites-4_3.pdf〉.

[25] Correia, J. R., Branco, F. a., Ferreira, J. G., Bai, Y., and Keller, T. (2010). "Fire protection systems for building floors made of pultruded GFRP profiles: Part 1: Experimental investigations." Composites Part B: Engineering, 41, 617-629. 
[26] Jeencham, R., Suppakarn, N., and Jarukumjorn, K. (2014). "Effect of flame retardants on flame retardant, mechanical, and thermal properties of sisal fiber/polypropylene composites.”

Composites Part B: Engineering, 56, 249-253.

[27] Liang, J. Z., Feng, J. Q., Tsui, C. P., Tang, C. Y., Liu, D. F., Zhang, S. D., and Huang, W. F. (2015). "Mechanical properties and flame-retardant of $\mathrm{PP} / \mathrm{MRP} / \mathrm{Mg}(\mathrm{OH})_{2} / \mathrm{Al}(\mathrm{OH})_{3}$ composites." Composites Part B: Engineering, 71, 74-81.

[28] Zhang, Z. X., Zhang, J., Lu, B. X., Xin, Z. X., Kang, C. K., and Kim, J. K. (2012). “Effect of flame retardants on mechanical properties, flammability and foamability of PP/wood-fiber composites." Composites Part B: Engineering, 43(2), 150-158.

[29] Chen, X., Yuan, L., Zhang, Z., Wang, H., Liang, G., and Gu, A. (2015). "New glass fiber / bismaleimide composites with significantly improved flame retardancy, higher mechanical strength and lower dielectric loss.” Composites Part B, Elsevier Ltd, 71, 96-102. 
Table 1: Material Properties of the Resin and ATH

\begin{tabular}{|c|c|c|c|c|c|}
\hline & Type & $\begin{array}{c}\text { Tensile } \\
\text { Strength } \\
(\mathbf{M P a})\end{array}$ & $\begin{array}{c}\text { Tensile } \\
\text { Modulus } \\
(\mathbf{G P a})\end{array}$ & $\begin{array}{c}\text { Compressive } \\
\text { Strength } \\
(\mathbf{M P a})\end{array}$ & Density \\
\hline Resin & 404 Isophthalic Resin & 50 & 37 & 88 & $1100 \mathrm{~kg} / \mathrm{m}^{3}$ \\
\hline ATH & A 202 & -- & -- & -- & $561 \mathrm{~kg} / \mathrm{m}^{3}$ \\
\hline $\begin{array}{c}\text { E-Glass } \\
\text { Fiber }\end{array}$ & Chopped Strand Mat & 2400 & 73 & -- & $2600 \mathrm{~kg} / \mathrm{m}^{3}$ \\
\hline
\end{tabular}

Table 2: Workability Results

\begin{tabular}{|c|c|c|}
\hline PPH & Workability & Comments \\
\hline 40 & 8 & \\
\hline 50 & 8 & \\
\hline 60 & 7 & \\
\hline 70 & 6 & \\
\hline 80 & 5 & honey like \\
\hline 90 & 4 & Un-pourable, still spreadable \\
\hline 100 & 4 & very un-pourable, still semi- \\
\hline 110 & 3 & spreadable \\
\hline 120 & 3 & waxy texture \\
\hline 130 & 2 & \\
\hline
\end{tabular}

Table 3: Loading Rates

\begin{tabular}{|c|c|c|}
\hline ASTM & Test & Loading Rate \\
\hline Modified D 695 & Compression & $1.3 \mathrm{~mm} / \mathrm{min}$ \\
\hline D790 & Flexure & $1.3 \mathrm{~mm} / \mathrm{min}$ \\
\hline D638 & Tension & $5.1 \mathrm{~mm} / \mathrm{min}$ \\
\hline C1292 & Shear & $8.4 \mathrm{~mm} / \mathrm{min}$ \\
\hline
\end{tabular}


Table 4: Maximum Force, Stress and Displacement for Compression

\begin{tabular}{|c|c|c|c|c|c|c|}
\hline \multirow{2}{*}{} & \multicolumn{4}{|c|}{ Control } & \multicolumn{3}{c|}{$\begin{array}{c}\text { Previous Research } \\
\text { (Chen and Davalos [10]) }\end{array}$} \\
\cline { 2 - 8 } & Average: & STDEV: & $\begin{array}{c}\text { COV } \\
(\%):\end{array}$ & Average: & STDEV: & $\begin{array}{c}\text { COV } \\
(\%):\end{array}$ \\
\hline Thickness (mm) & 7.9 & 0.3 & 4 & --- & --- & --- \\
\hline Max Load (kN): & 16 & 1 & 8 & --- & --- & --- \\
\hline Max Stress (MPa): & 178 & 18 & 10 & 148 & 4 & 3 \\
\hline Max $\Delta(\mathrm{mm}):$ & 2.41 & 0.26 & 11 & --- & --- & --- \\
\hline Stiffness E (MPa): & 6758 & 535 & 8 & 8605 & --- & --- \\
\hline $\begin{array}{c}\text { Max Strain } \\
\text { (mm/mm) }\end{array}$ & 0.026 & --- & --- & --- & --- & --- \\
\hline & \multicolumn{7}{|c|}{$25 \%$ ATH } & & & $50 \%$ ATH & \\
\cline { 2 - 8 } & Average: & STDEV: & $\begin{array}{c}\text { COV } \\
(\%):\end{array}$ & Average: & STDEV: & $\begin{array}{c}\text { COV } \\
(\%):\end{array}$ \\
\hline Thickness (mm) & 7.6 & 0.3 & 4 & 10.3 & 0.4 & 4 \\
\hline Max Load (kN): & 14 & 2 & 13 & 17 & 2 & 13 \\
\hline Max Stress (MPa): & 145 & 17 & 12 & 138 & 15 & 11 \\
\hline Max $\Delta(\mathrm{mm}):$ & 2.11 & 0.20 & 11 & 2.56 & 0.51 & 20 \\
\hline Stiffness E (MPa): & 6402 & 368 & 6 & 6509 & 879 & 13 \\
\hline $\begin{array}{c}\text { Max Strain } \\
\text { (mm/mm) }\end{array}$ & 0.022 & --- & --- & 0.021 & --- & --- \\
\hline
\end{tabular}

Table 5: Average Maximum Force, Stress and Displacement for Tension

\begin{tabular}{|c|c|c|c|c|c|c|}
\hline & \multicolumn{3}{|c|}{ Control } & \multicolumn{3}{c|}{ Previous Research } \\
\cline { 2 - 8 } & Average: & STDEV: & COV $(\%):$ & Average: & STDEV: & COV $(\%):$ \\
\hline Thickness (mm) & 5.8 & 0.5 & 8 & -- & -- & -- \\
\hline Max Load (N): & 8603 & 159 & 2 & -- & -- & -- \\
\hline Max Stress (MPa): & 122 & 8 & 7 & 128 & -- & -- \\
\hline Max $\Delta(\mathrm{mm}):$ & 4.5 & 0.06 & 1 & -- & -- & -- \\
\hline Stiffness E (MPa): & 5981 & 255 & 4 & 6469 & -- & -- \\
\hline $\begin{array}{c}\text { Max Strain } \\
(\mathrm{mm} / \mathrm{mm})\end{array}$ & 0.020 & -- & -- & -- & -- & -- \\
\hline & \multicolumn{7}{|c|}{$25 \%$ ATH } & & & $50 \%$ ATH \\
\cline { 2 - 9 } & Average: & STDEV: & COV $(\%):$ & Average: & STDEV: & COV $(\%):$ \\
\hline Thickness (mm) & 5.6 & 0.5 & 9 & 5.6 & 0.2 & 4 \\
\hline Max Load (N): & 7913 & 1051 & 13 & 4667 & 194 & 4 \\
\hline Max Stress (MPa): & 110 & 5 & 4 & 65 & 5 & 8 \\
\hline Max $\Delta(\mathrm{mm}):$ & 4.0 & 0.5 & 13 & 3.3 & 0.2 & 6 \\
\hline Stiffness E (MPa): & 6330 & 815 & 13 & 5710 & 848 & 15 \\
\hline $\begin{array}{c}\text { Max Strain } \\
(\mathrm{mm} / \mathrm{mm})\end{array}$ & 0.017 & -- & -- & 0.011 & -- & - \\
\hline
\end{tabular}


Table 6: Average Maximum Force, Stress and Displacement for Shear

\begin{tabular}{|c|c|c|c|c|c|c|}
\hline \multirow{2}{*}{} & \multicolumn{3}{|c|}{ Control } & \multicolumn{3}{c|}{$\begin{array}{c}\text { Previous Research } \\
\text { (Chen and Davalos [10]) }\end{array}$} \\
\cline { 2 - 8 } & Average: & STDEV: & COV $(\%):$ & Average: & STDEV: & COV (\%): \\
\hline Thickness (mm) & 7.5 & 0.2 & 2 & -- & -- & -- \\
\hline Max Load (N): & 7037 & 395 & 6 & -- & -- & -- \\
\hline Max Stress (MPa): & 83 & 5 & 7 & 71 & 3 & 4 \\
\hline Max $\Delta(\mathrm{mm}):$ & 2.0 & 0.2 & 11 & -- & -- & -- \\
\hline & \multicolumn{3}{|c|}{$25 \%$ ATH } & \multicolumn{3}{c|}{$50 \%$ ATH } \\
\cline { 2 - 8 } & Average: & STDEV: & COV $(\%):$ & Average: & STDEV: & COV (\%): \\
\hline Thickness (mm) & 7.8 & 0.3 & 4 & 11.0 & 0.5 & 4 \\
\hline Max Load (N): & 7229 & 1016 & 14 & 7627 & 431 & 6 \\
\hline Max Stress (MPa): & 82 & 10 & 12 & 61 & 1 & 2 \\
\hline Max $\Delta(\mathrm{mm}):$ & 2.0 & 0.1 & 6 & 1.4 & 0.1 & 8 \\
\hline
\end{tabular}

Table 7: Average Maximum Force, Stress and Displacement for Flexure

\begin{tabular}{|c|c|c|c|c|c|c|}
\hline & \multicolumn{3}{|c|}{ Control } & \multicolumn{3}{|c|}{$25 \%$ ATH } \\
\hline & Average: & STDEV: & $\operatorname{COV}(\%):$ & Average: & STDEV: & $\operatorname{COV}(\%)$ \\
\hline Thickness (mm) & 7.3 & 0.3 & 5 & 7.4 & 0.5 & 7 \\
\hline $\operatorname{Max} \operatorname{Load}(\mathrm{N}):$ & 871 & 5 & 0.5 & 940 & 99 & 11 \\
\hline Max Stress (MPa): & 132 & 18 & 13 & 136 & 9 & 7 \\
\hline $\operatorname{Max} \Delta(\mathrm{mm}):$ & 41.6 & 2.2 & 6 & 41.5 & 2.6 & 6 \\
\hline \multirow[t]{3}{*}{ Stiffness E (MPa): } & 7741 & 928 & 12 & 7739 & 511 & 7 \\
\hline & \multicolumn{3}{|c|}{$50 \%$ ATH } & & & \\
\hline & Average: & STDEV: & $\operatorname{COV}(\%):$ & & & \\
\hline Thickness (mm) & 10.0 & 0.3 & 3 & & & \\
\hline $\operatorname{Max} \operatorname{Load}(\mathrm{N}):$ & 1319 & 127 & 10 & & & \\
\hline Max Stress (MPa): & 104 & 12 & 11 & & & \\
\hline $\operatorname{Max} \Delta(\mathrm{mm})$ & 32.0 & 2.9 & 9 & & & \\
\hline Stiffness E (MPa): & 6877 & 499 & 7 & & & \\
\hline
\end{tabular}




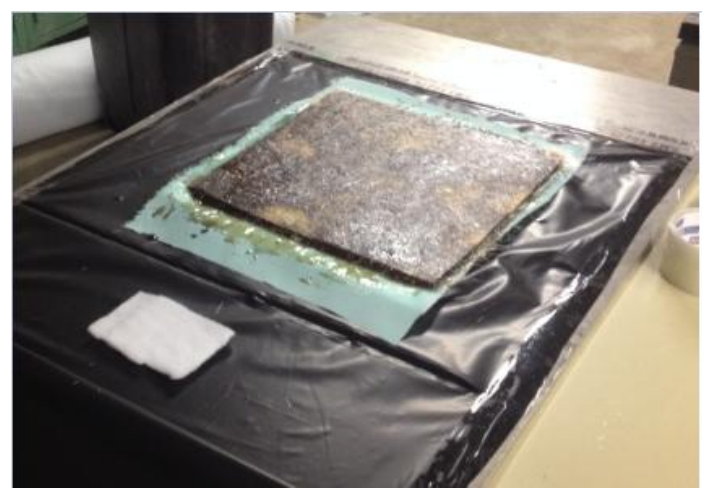

(A) FRP sealing bag

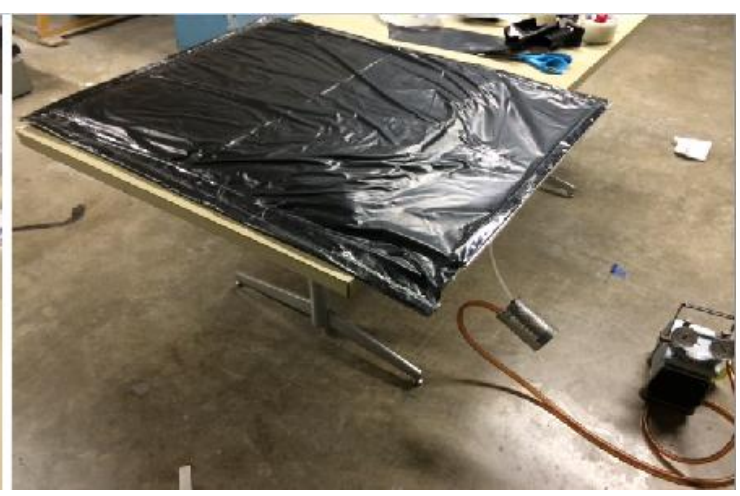

(B) After sealing bag

Figure 1: Vacuum Bagging Process

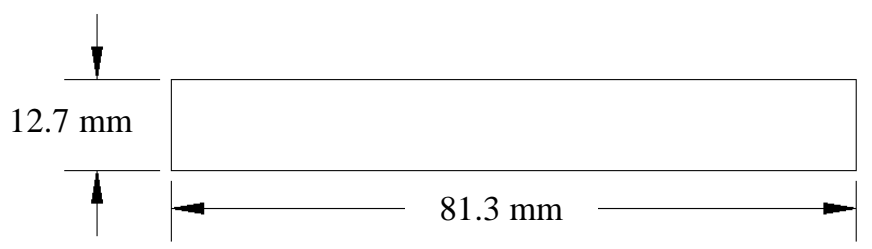

Figure 2: Compression Dimensions

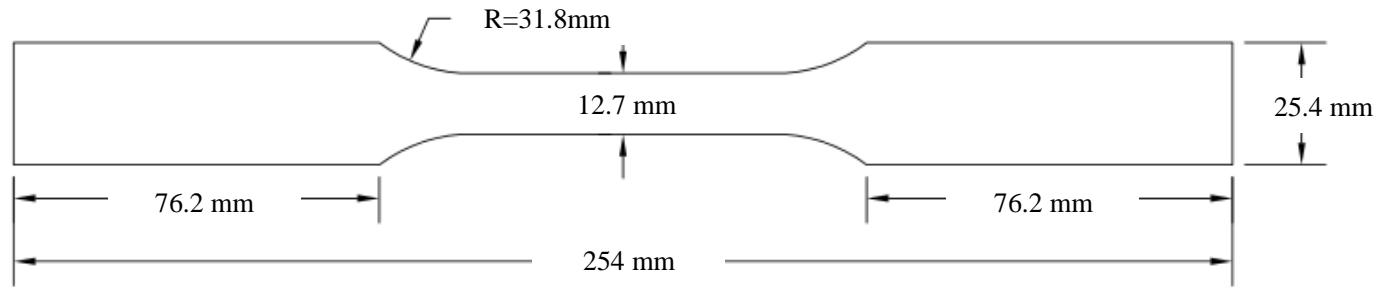

Figure 3: Tension Dimensions

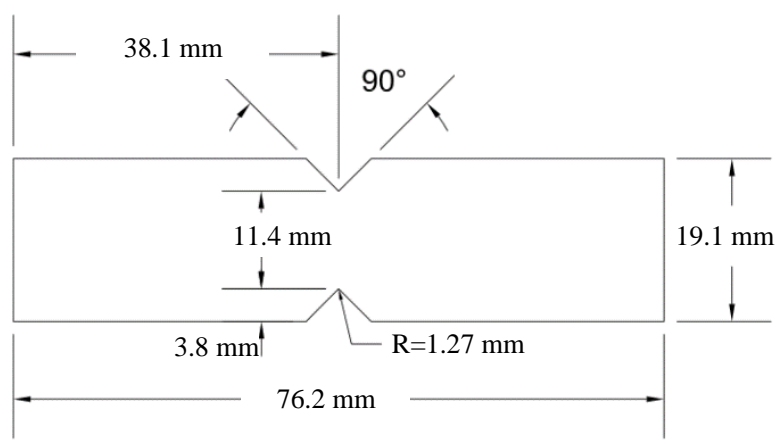

Figure 4: Shear Dimensions 
Figure 6: Compression Testing Fixture

Figure 7: Tension Testing Fixture and Failed Tension Sample

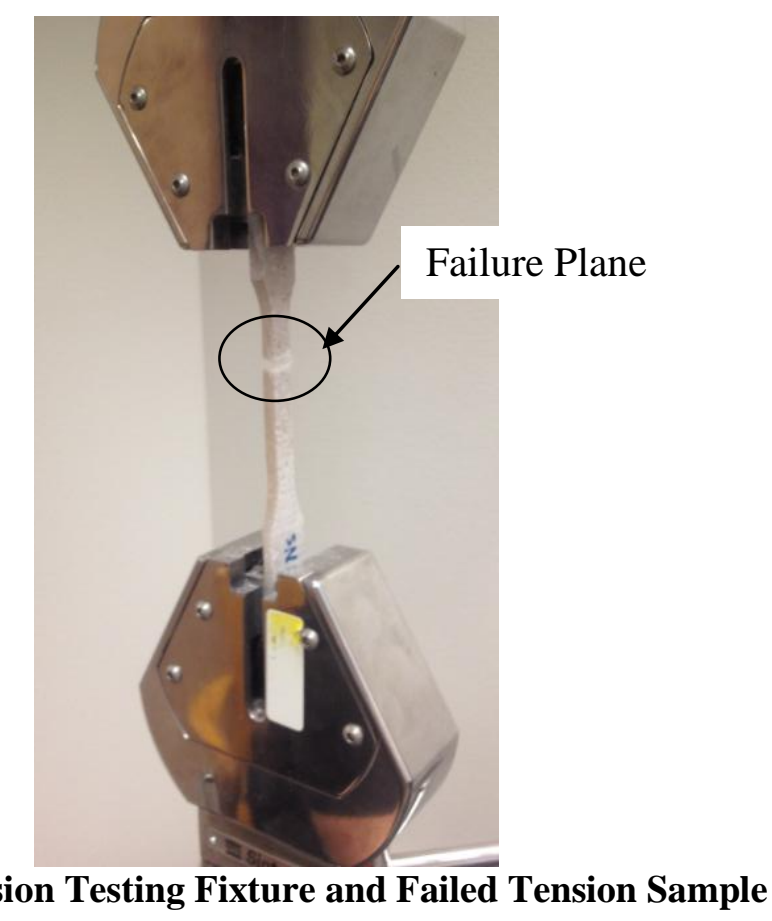




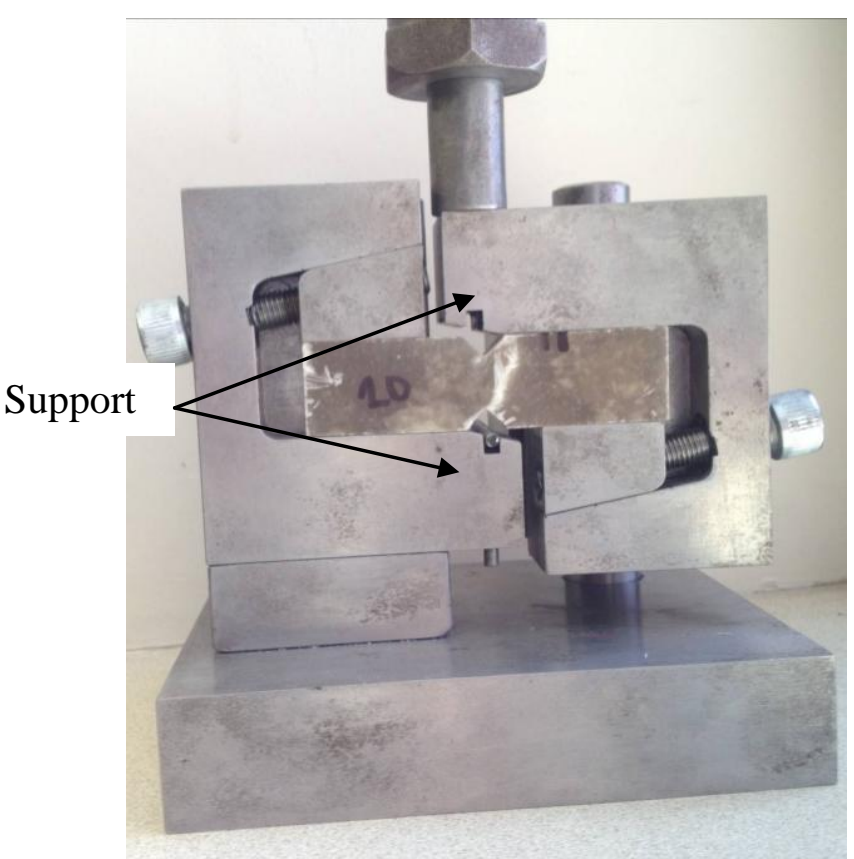

Figure 8: Shear Testing Fixture and Failed Sample

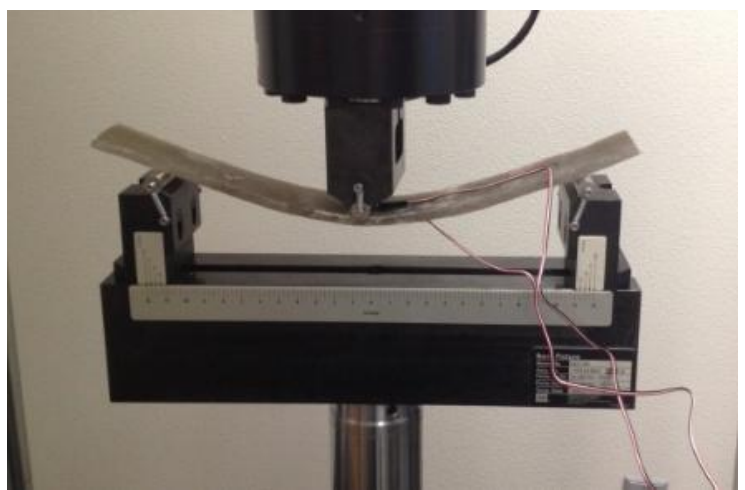

Figure 9: Flexural Testing Fixture

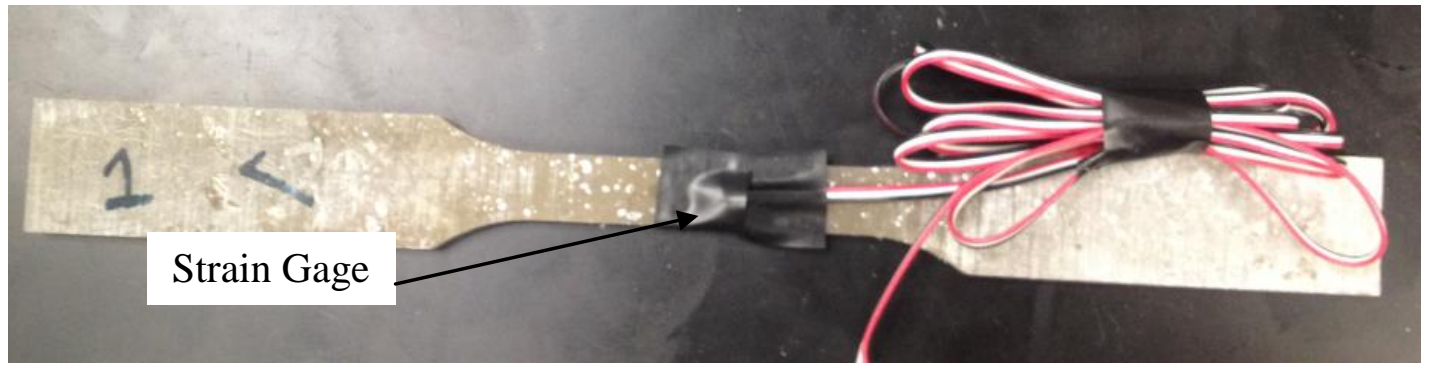

Figure 10: Placement of Tension Strain Gage 
Figure 11: Placement of Flexure Strain Gage

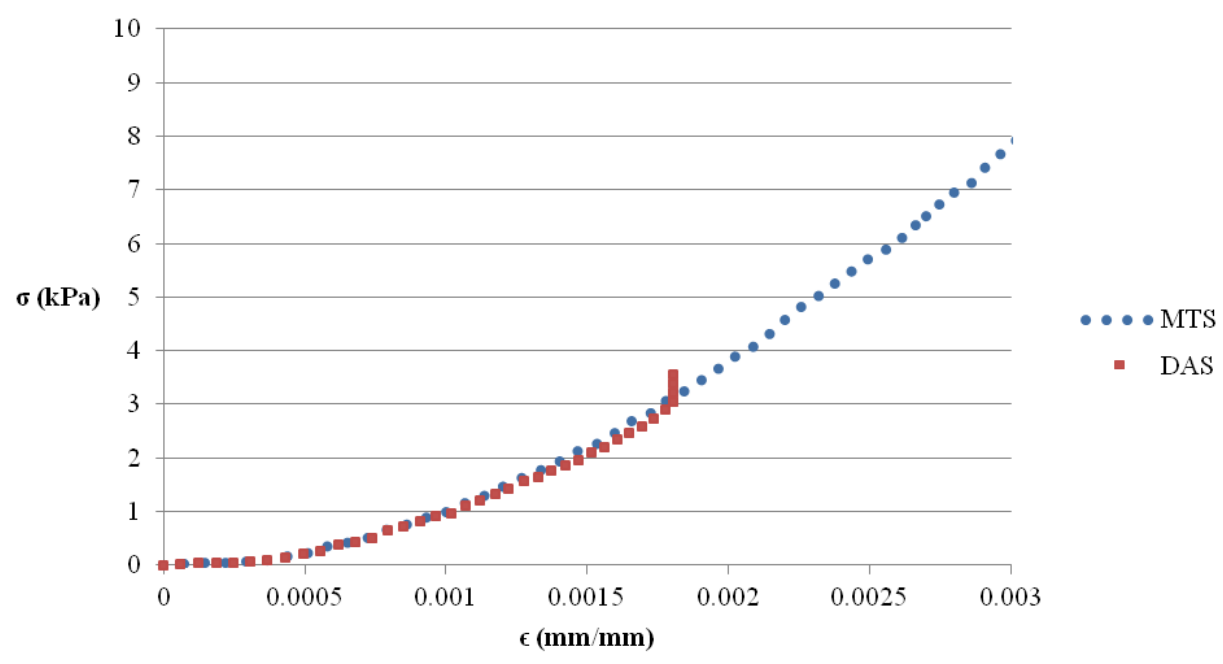

Figure 12: MTS vs. DAS for Compression with 50\% ATH

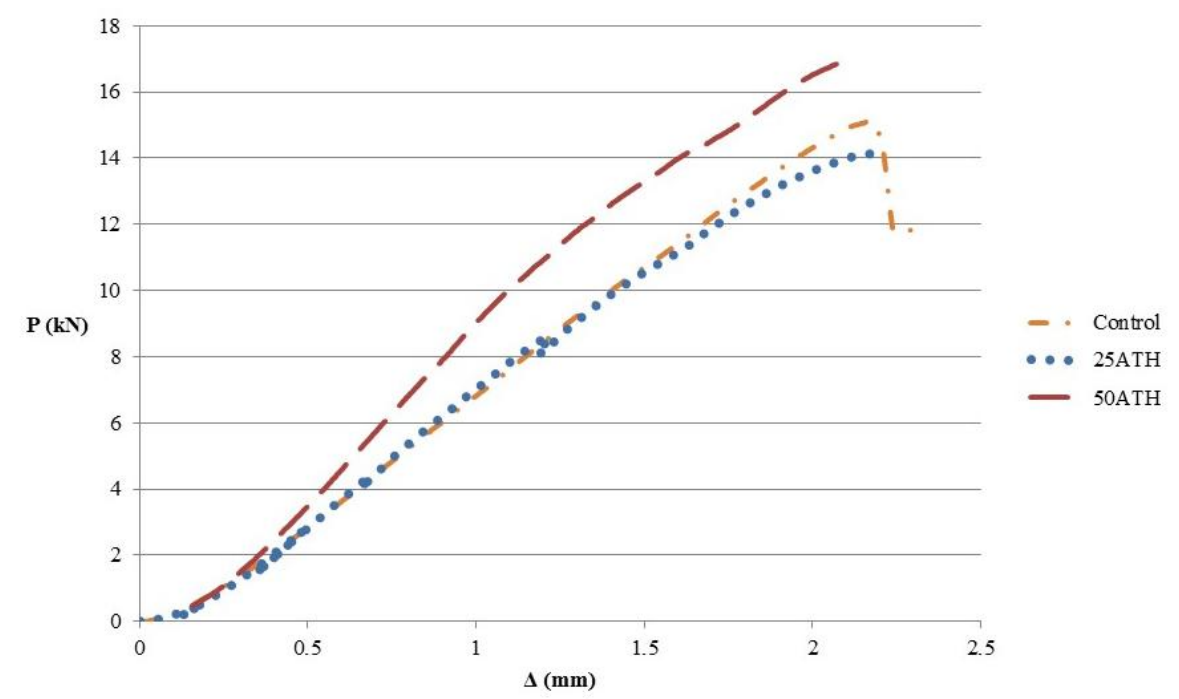

Figure 13: Force-Displacement Curves for Compression 


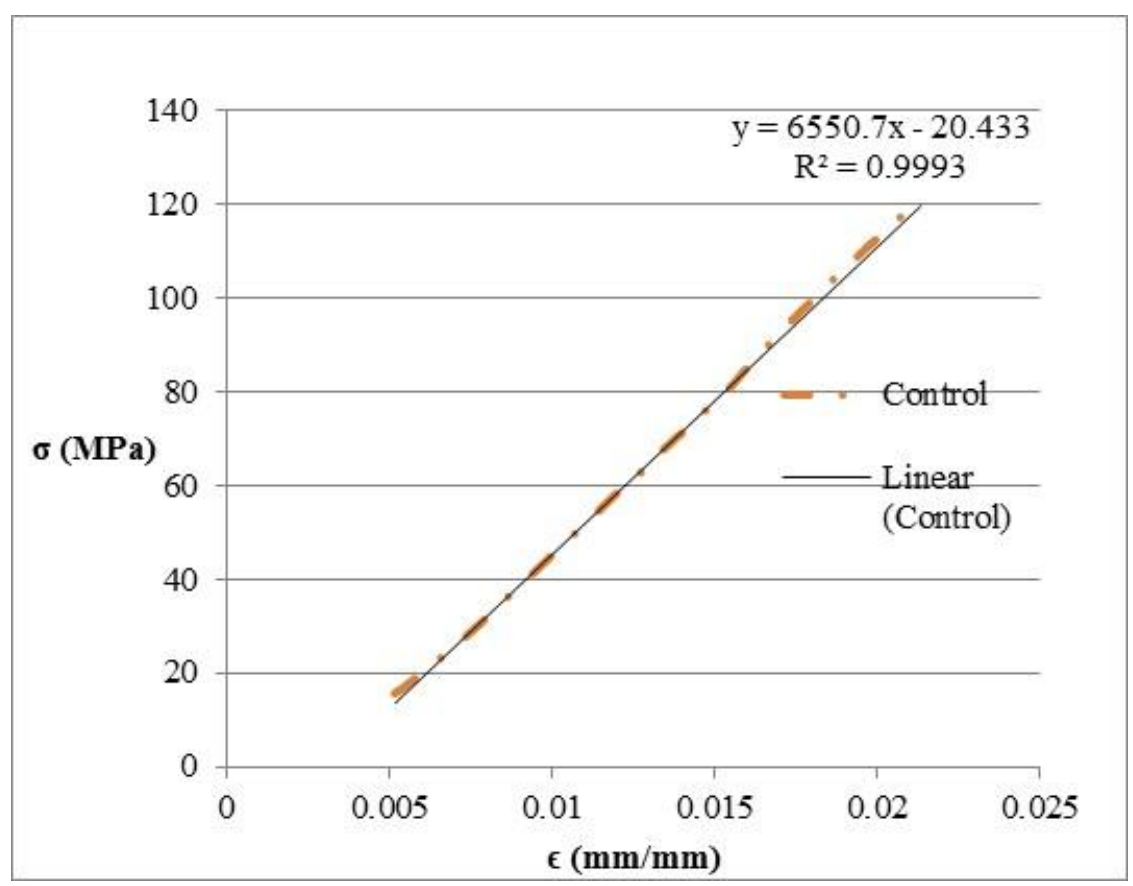

Figure 15: Stiffness Calculation 


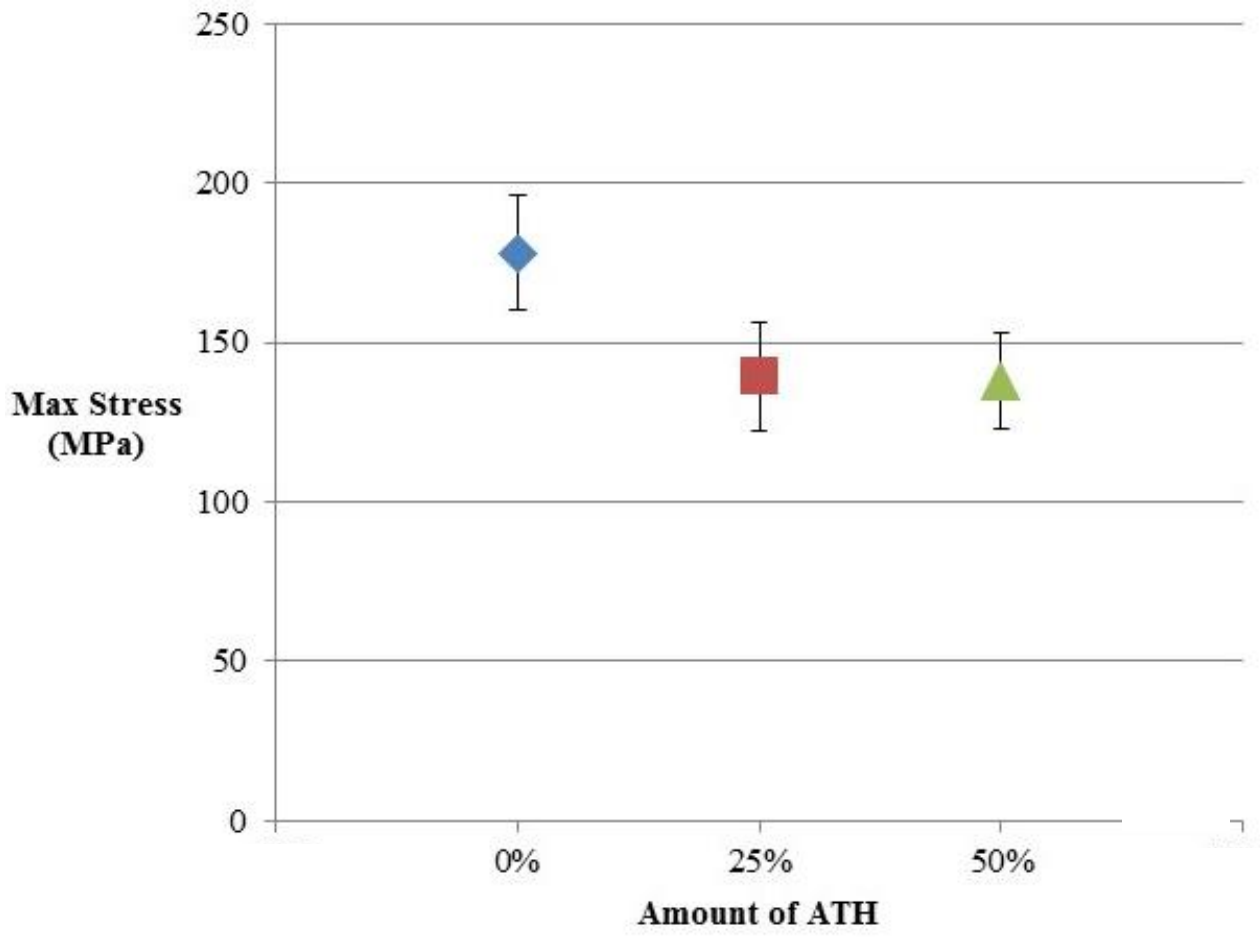

Figure 17: Max Compressive Stress with Error Bounds 


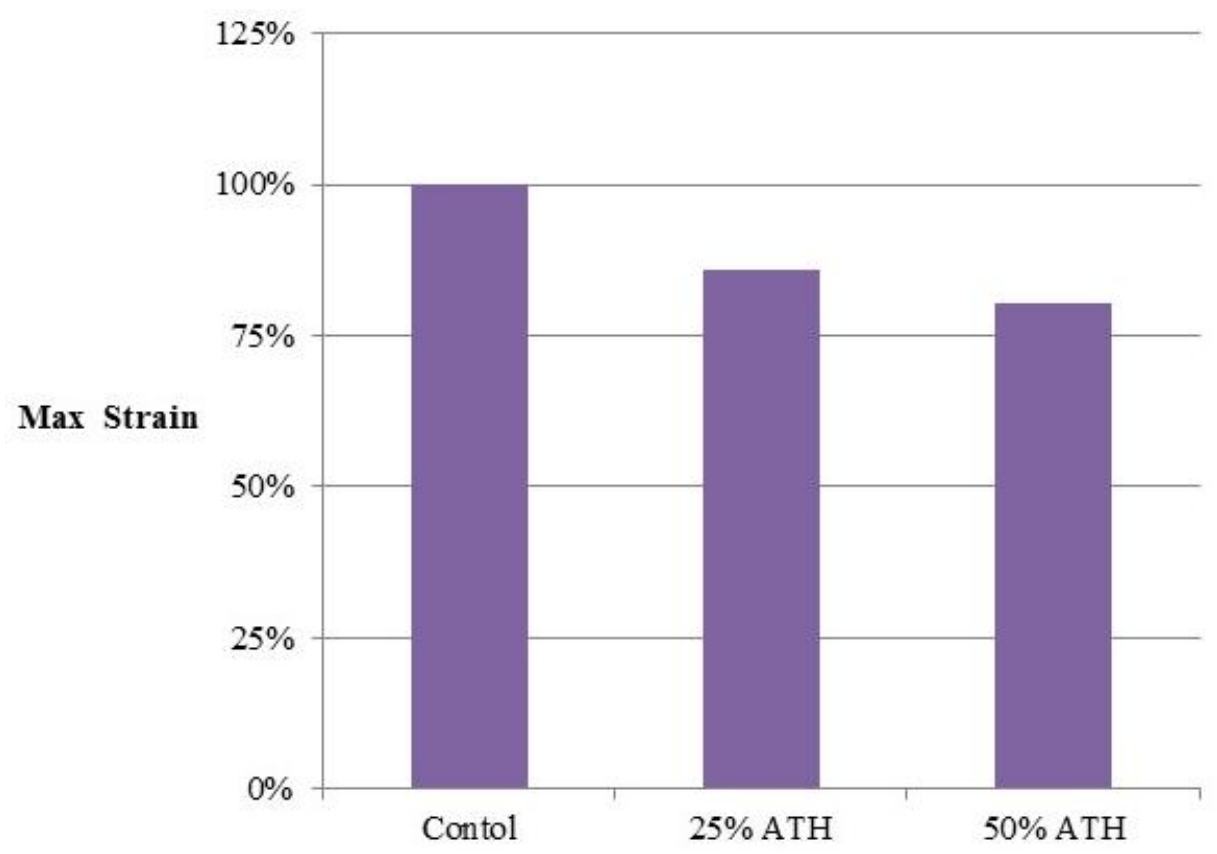

Figure 18: Comparison of Maximum Strain for Compression

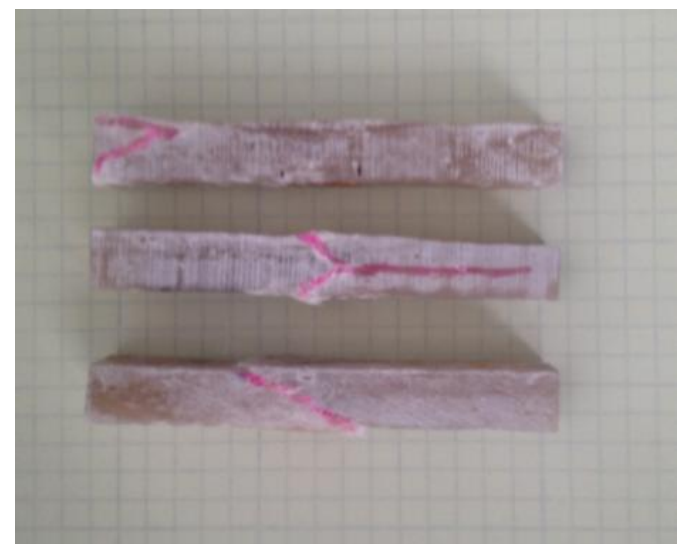

Figure 19: Failure Mode 


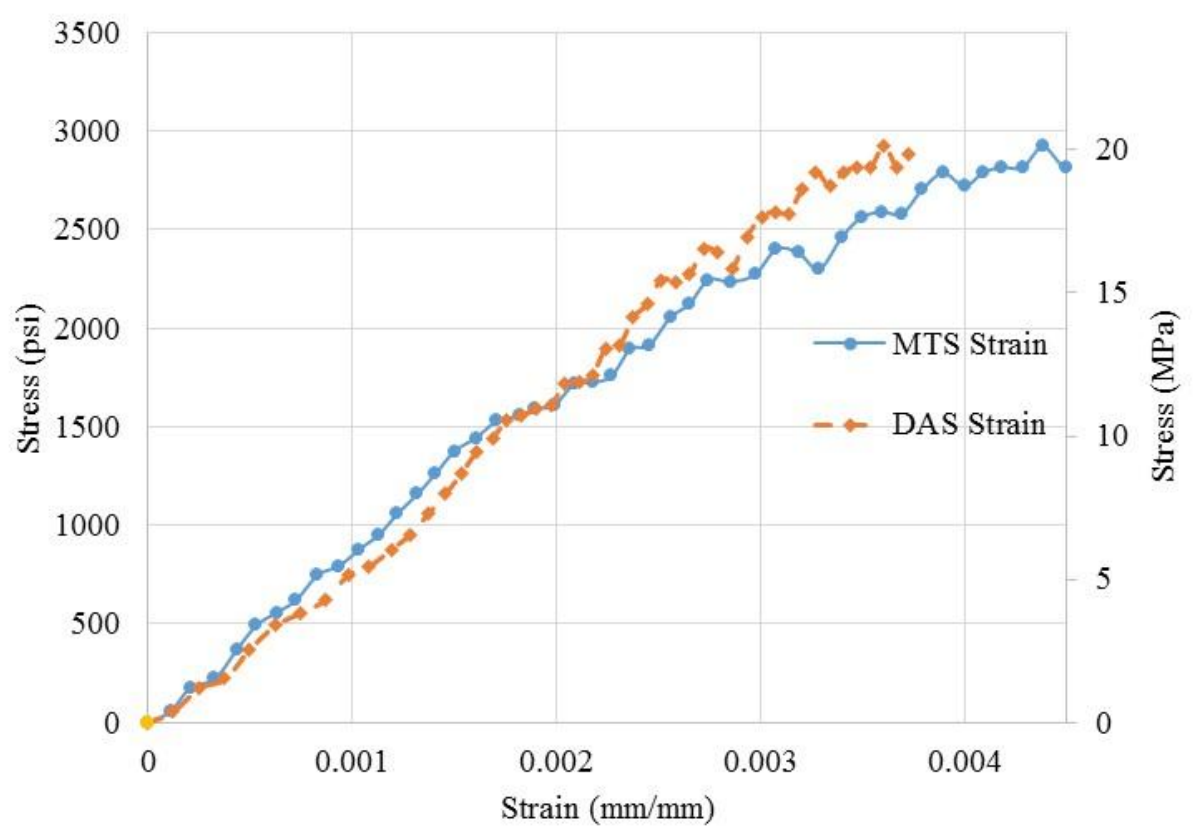

Figure 20: MTS vs. DAS for Tension with 50\% ATH

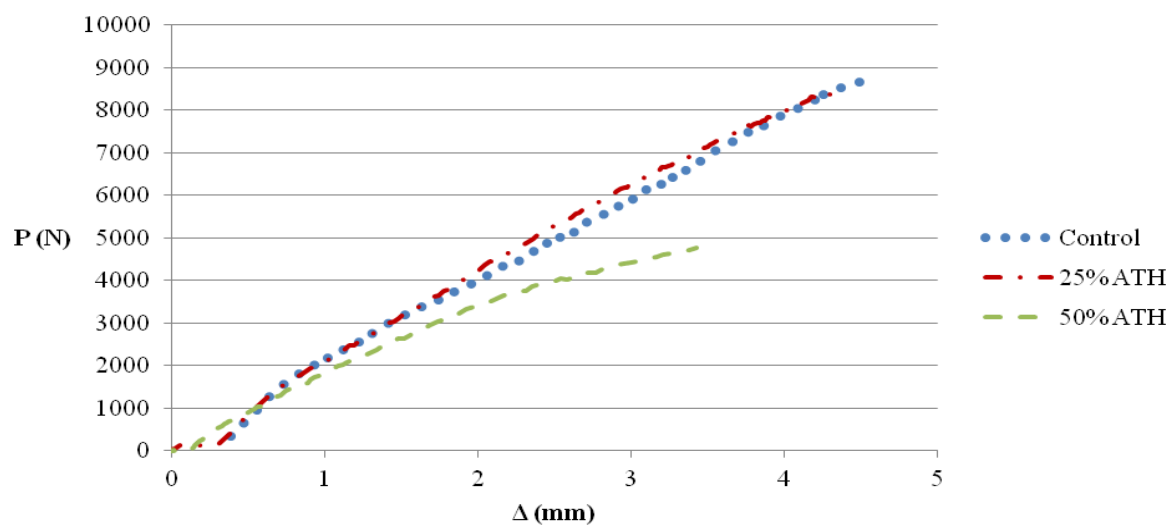

Figure 21: Force-Displacement Curves for Tension 


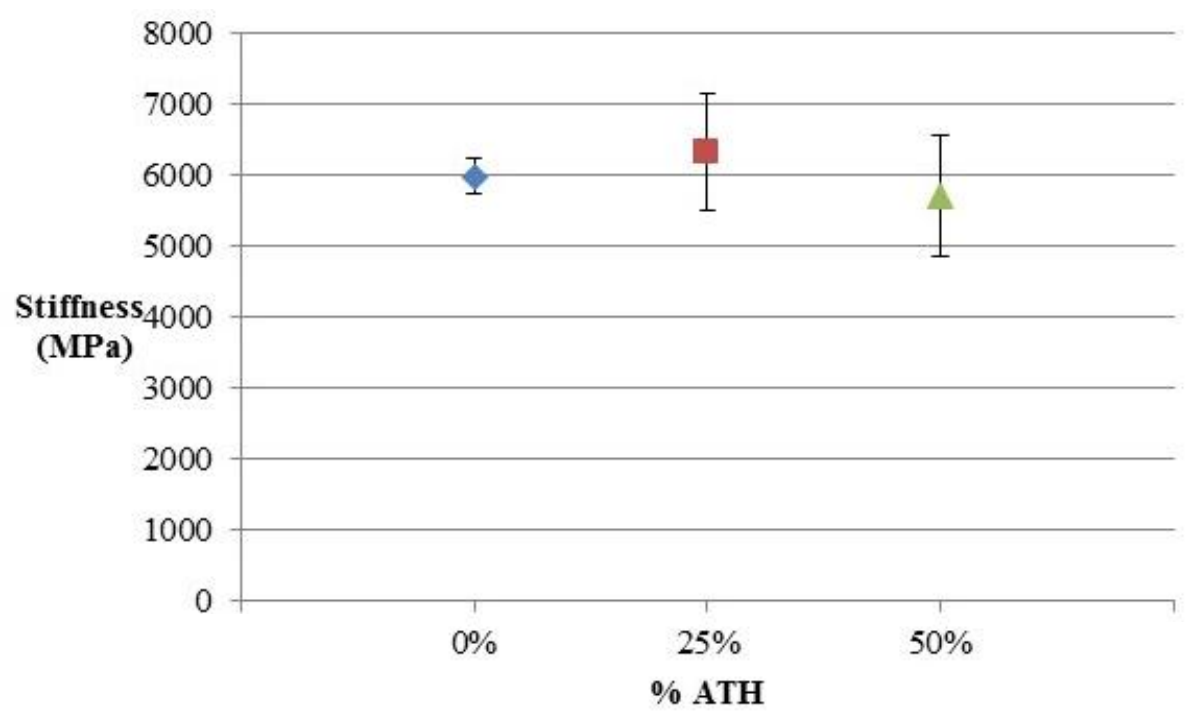

Figure 23: Comparison of Tensile Modulus of Elasticity 


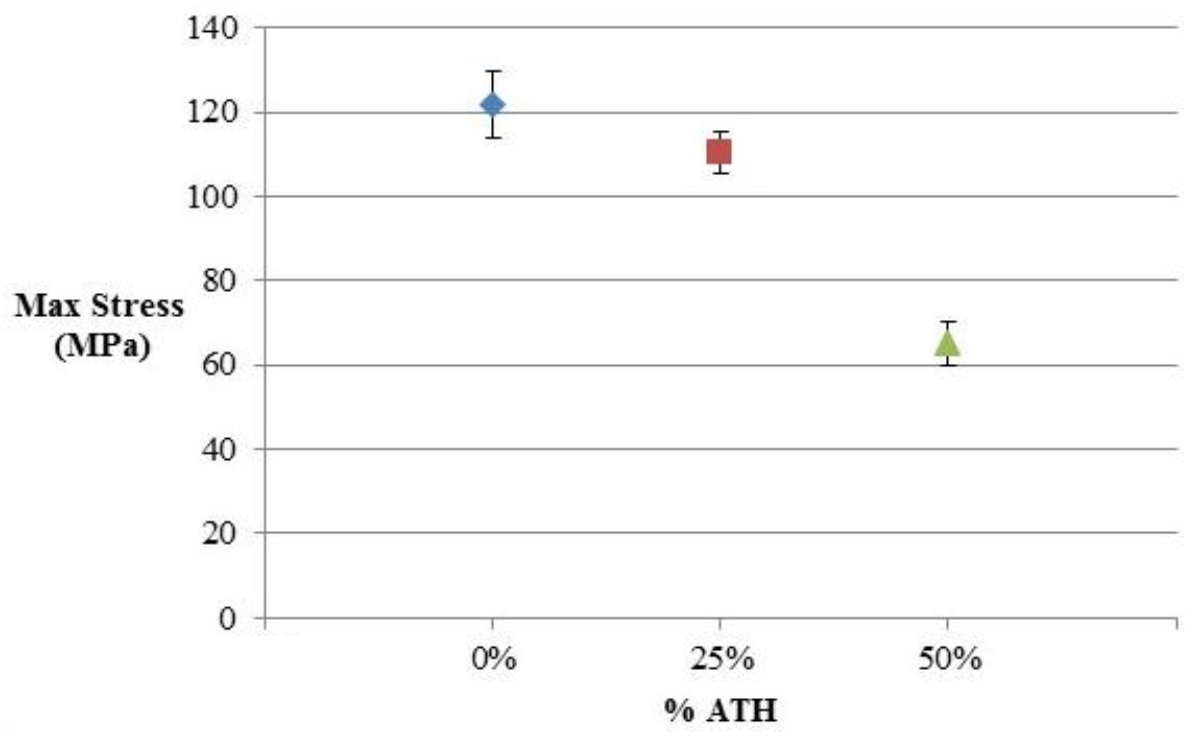

Figure 24: Max Tensile Stress with Error Bounds

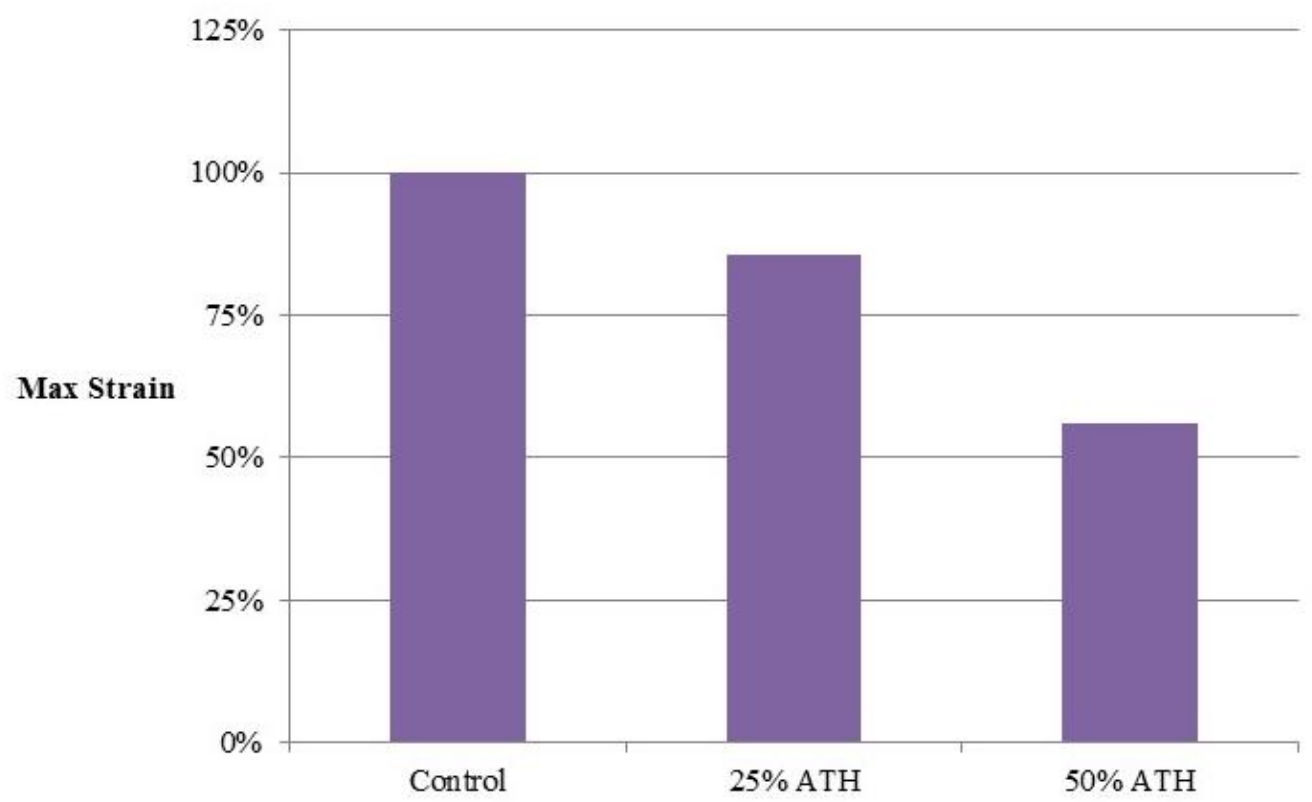

Figure 25: Comparison of Maximum Strain for Tension

Figure 26: Failure Mode 


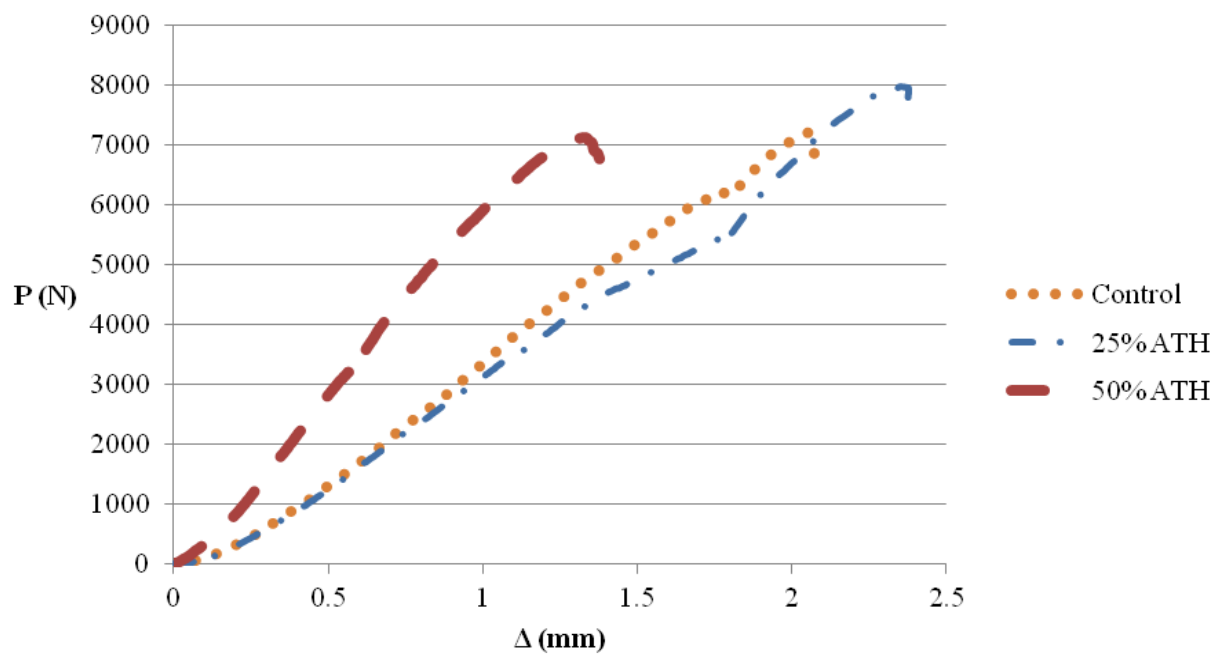

Figure 27: Force-Displacement Curves for Shear

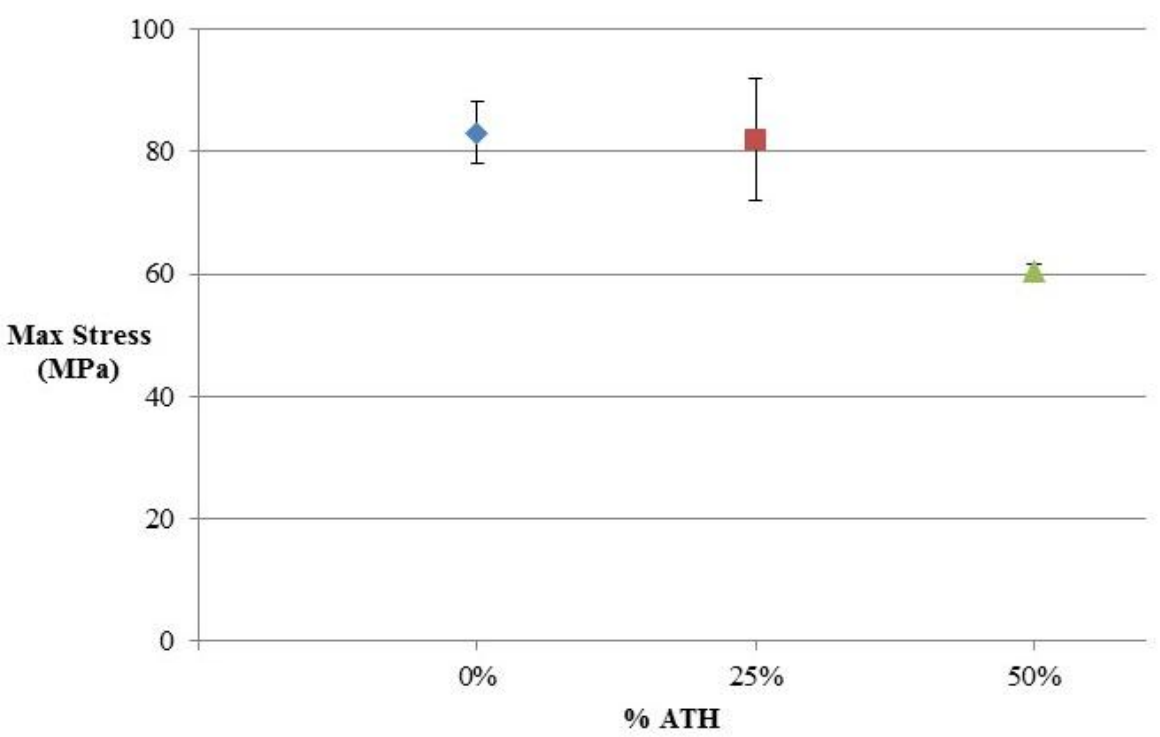

Figure 28: Max Shear Stress with Error Bounds 


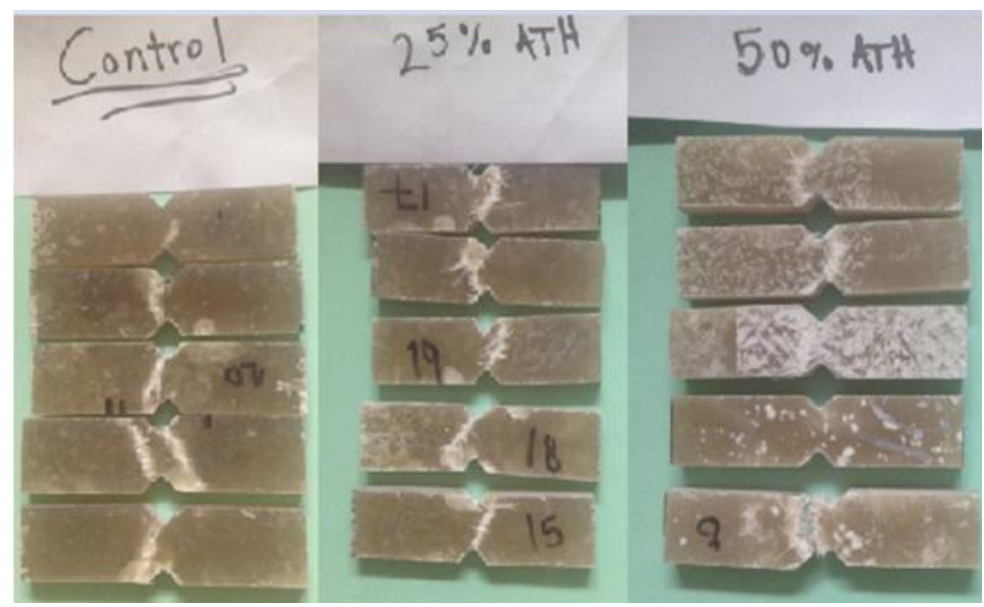

(A)

(B)

(C)

Figure 29: Failure Mode for (A) Control, (B) 25\% ATH, (C) 50\% ATH

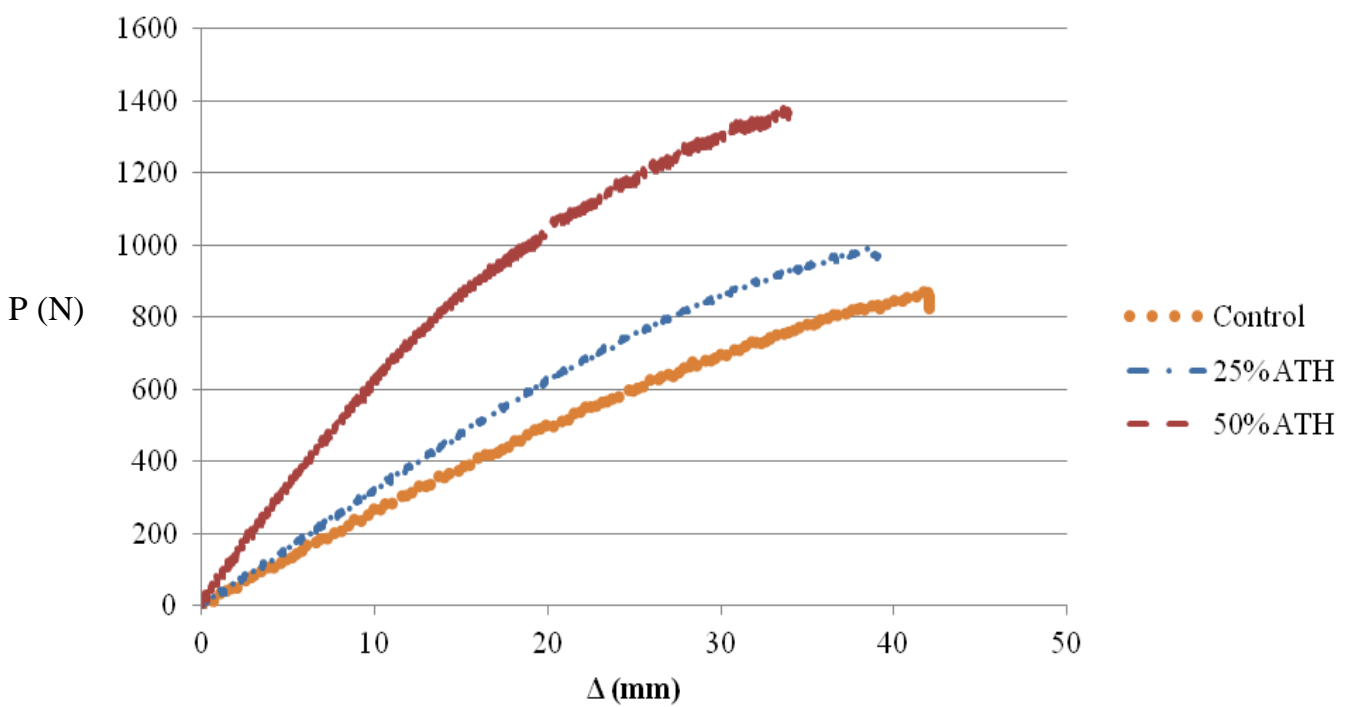

Figure 30: Force-Displacement Curves for Flexure 


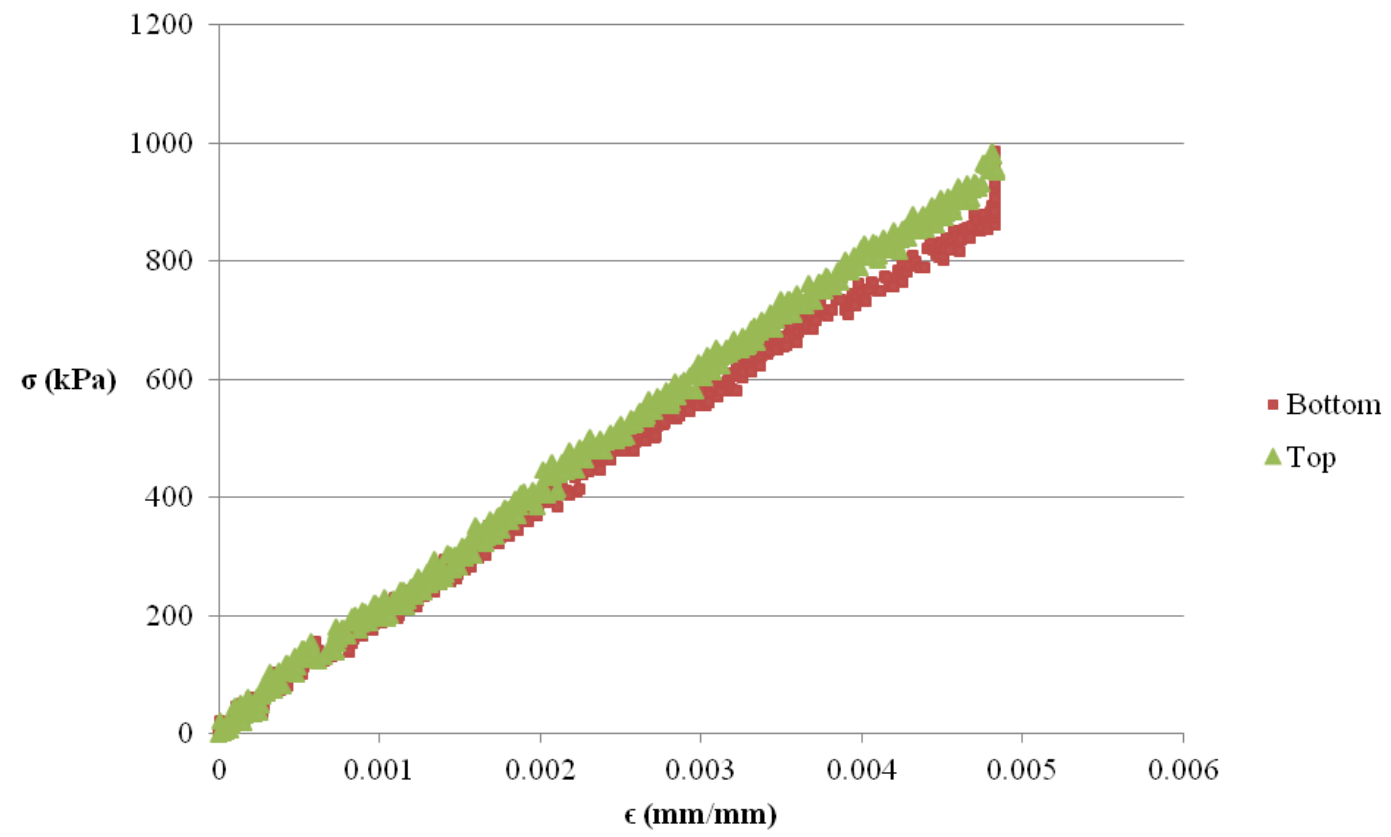

Figure 31: Control Stress-Strain Curve from DAS

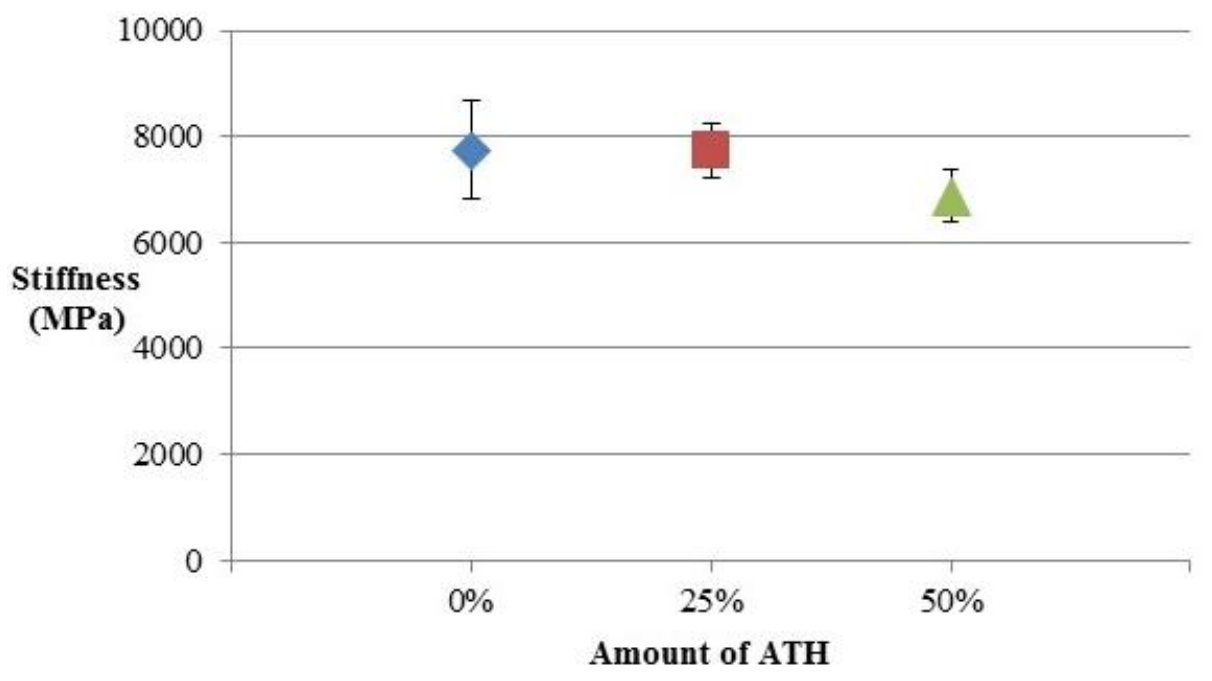

Figure 32: Comparison of Flexural Modulus of Elasticity 


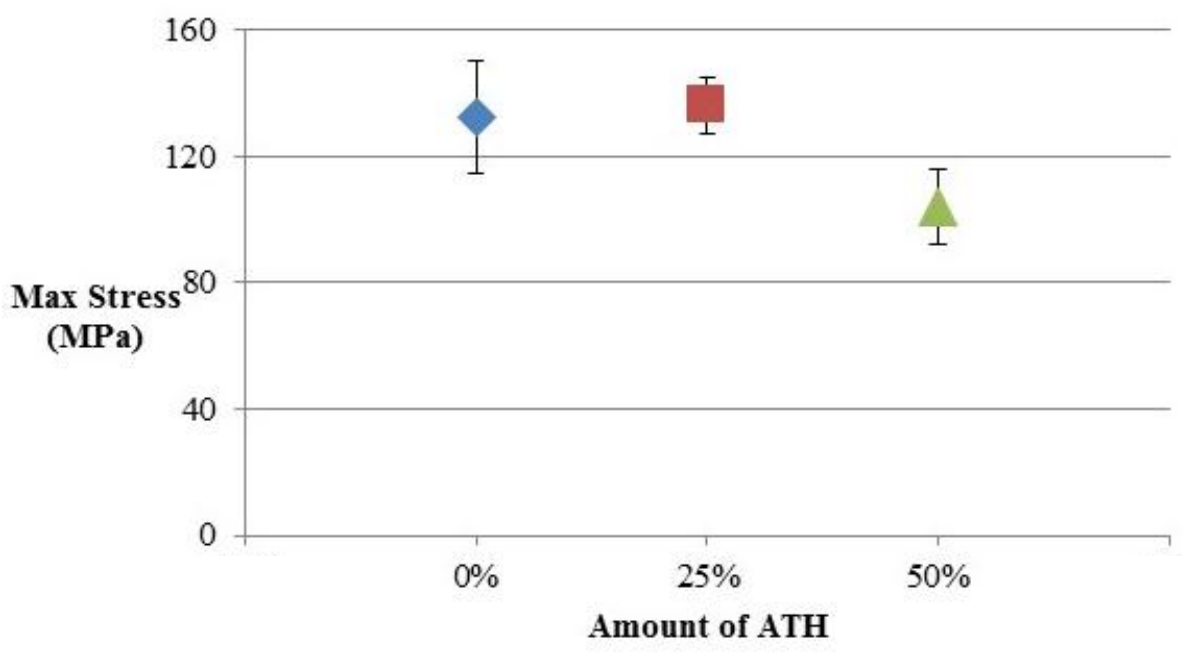

Figure 33: Comparison of Maximum Flexural Stress

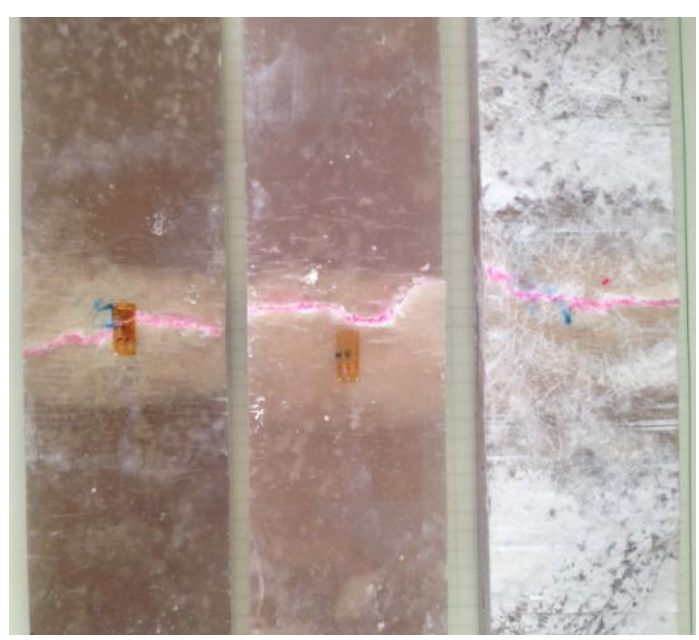
(A)
(B)
(C)

Figure 34: Failure Mode, Bottom View of (A) Control, (B) 25\% ATH, (C) 50\% ATH

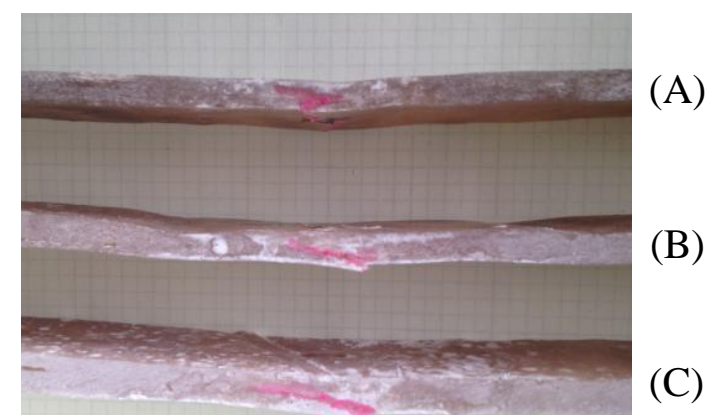

Figure 35: Failure Mode, Side View of (A) Control, (B) 25\% ATH, (C) 50\% ATH 